\title{
Synthesis And Evaluation of Ca-Doped Ferrihydrite As A Novel Adsorbent For The Efficient Removal of Fluoride
}

Khalil ahmad ( $\square$ ahmadkhalil9012@gmail.com )

East China Normal University

Izaz Ali Shah

Beijing Normal University

Sharafat Ali

Beijing Normal University

Muahammad Tariq Khan

The Education University of Hong Kong

Muhammad Bilal Ahmed Qureshi

Beijing Normal University

Syed Hassan Ali Shah

Beijing Normal University

\section{Asmat Ali}

China University of Geosciences

\section{Wajid Rashid}

University of Swat

Hifza Nayab Gul

East China Normal University

\section{Research Article}

Keywords: adsorption, Ca-doped ferrihydrite, Fluoride, novel adsorbent, Water treatment

Posted Date: May 26th, 2021

DOI: https://doi.org/10.21203/rs.3.rs-473279/v1

License: (1) (i) This work is licensed under a Creative Commons Attribution 4.0 International License.

Read Full License

Version of Record: A version of this preprint was published at Environmental Science and Pollution Research on August 27th, 2021. See the published version at https://doi.org/10.1007/s11356-021-16105- 
Page $2 / 26$ 


\section{Abstract}

In this work, a novel calcium (Ca) doped ferrihydrite adsorbent was evaluated for the enhanced adsorption of fluoride (F) from the aqueous phase. The adsorbent properties, adsorption behavior, and mechanism were systematically evaluated. The synthesized adsorbent exhibited tremendous performance in a broad range of temperature and $\mathrm{pH}$. Interestingly, the presence of co-existing anions such as $\mathrm{NO}_{3}{ }^{-}, \mathrm{SO}_{4}{ }^{2-}, \mathrm{Cl}^{-}$, and natural organic matter (NOM) have no considerable effect on the adsorption of fluoride from water. The adsorption process was best fitted to the pseudo-second order kinetic model and the Langmuir isotherm. The prepared adsorbent exhibited a maximum adsorption capacity of 53.21 $\mathrm{mg} / \mathrm{g}$ for the uptake of fluoride from water. The regeneration results confirmed that adsorbent could retain their original adsorption capacity after five regeneration cycles. Results from the current study suggested that Ca-doped ferrihydrite has the application potential for the enhanced adsorption of fluoride from the water phase.

\section{Introduction}

Fluoride is an essential element for the growth of the skeleton and teeth in the human body (Pillai et al. 2020; Tao et al. 2020). However, it can also cause various health problems, if used in excessive amounts. Likewise, fluoride is also an important element for flora and fauna; however, its presence in high concentration can adversely affect the various biological process in plants (Gao et al. 2020). In recent years, the occurrence of fluoride in the aqueous environment has raised serious environmental and public health concerns, due to their toxic adverse effects on the biological and ecological environment (Thompson et al. 2007; Ali et al. 2019). In our geological environment fluoride is widely distributed (Amini et al. 2008). Globally around two hundred million people are living in regions with elevated fluoride concentrations in drinking water (Amini et al. 2008; Gao et al. 2020). The primary sources of fluoride are fluoride-rich rocks. As per WHO guidelines, the permissible level of fluoride content in drinking water is 1.5 $\mathrm{mg} / \mathrm{L}$ (santé et al. 2004).

The concentration of fluoride in water has a direct relation to the magnitude of leaching/dissolution of fluoride-rich rock by water and rock interaction. Generally, the process of dissolution of fluoride rick rocks is slow (Banks et al. 1995; Jadhav et al. 2015). Fluoride concentration and occurrence in water resources depends on many factors (Karthikeyan and Shunmugasundarraj 2000; Subba Rao 2003). In groundwater, it depends upon total dissolved solids, $\mathrm{pH}$, hardness, alkalinity, and geochemical configuration of the water table (Rafique et al. 2008; Abdelgawad et al. 2009). Apart from the entrance of fluoride in water through the natural process, in many countries over the globe elevated concentration of fluoride in water is just because of different industry wastewater which contains fluorine. Such kind of wastewater are generally produced by ceramic and glass manufacturing process (Ponsot et al. 2013), fertilizers industry (Mourad et al. 2009), zinc, and aluminum smelters (Blagojević et al. 2002; Shen et al. 2003), oil refineries(Khatibikamal et al. 2010), coal-fired power stations, uranium enrichment facilities, beryllium extraction plants, steel production, waste incineration plants, semiconductors production (Hu et al. 2005; Warmadewanthi and Liu 2009; Bhatnagar et al. 2011), photovoltaic solar cell industry (Drouiche et al. 
2013), fluorinated textiles, and through the decomposition of $\mathrm{CaF}_{2}$ in waste sludge (Habuda-Stanić et al. 2014).

Conventional treatment technologies employed for the elimination of fluoride from water include chemical precipitation (Amini et al. 2008), ion exchange (Cai et al. 2015), coagulation and electrocoagulation (Khatibikamal et al. 2010), membrane filtration (Jadhav et al. 2015), electrodialysis (Subba Rao 2003), and adsorption (Abdelgawad et al. 2009). Among the commonly used technologies, adsorption is considered a promising and widely used treatment technology for the enhanced removal of various pollutants from water, due to their process simplicity, high efficiency, and cost-effectiveness (Rafique et al. 2008; Naushad 2014; Ihsanullah et al. 2015, 2016a, b; Aamir et al. 2016; Asmaly et al. 2016; Khalid et al. 2018; Balasubramani et al. 2020; Ihsanullah 2020; Zubair et al. 2020). A variety of adsorbents are being employed for the removal of fluoride including cow and fishbone char (Brunson and Sabatini 2009), goethite (Tang et al. 2010), aluminum hydroxide (Parmar et al. 2006), magnetic cationic hydrogel (Dong and Wang 2016), hydroxyapatite (He et al. 2016), $\mathrm{CeO}_{2}$ (Kang et al. 2017), and $\mathrm{HCl}-$ activated red mud (Çengeloğlu et al. 2002). However, several technical drawbacks hindered the widespread use and applications of the synthesized adsorbents for the enhanced removal of fluoride from feedwater. Therefore, the currently used treatment techniques for the uptake of fluoride from water often considered being inefficient because of their high requirements on engineering expertise and supporting infrastructure, thereby precluding their uses and applications around the world.

Recently, ferrihydrite-based adsorbents have gained considerable attention due to exceptional removal performance toward both anions and cations (Rout et al. 2012; Gomez et al. 2013; Liu et al. 2020; Van Eynde et al. 2020), but the adsorption capacity of ferrihydrite for fluoride is not significant (Kumar et al. 2009; Nur et al. 2014). Calcium-based adsorbents have been emerging as novel contenders for the enhanced uptake of fluoride from source water (Turner et al. 2005; Islam and Patel 2007; Jain and Jayaram 2009). Therefore, it is important to fabricate a novel adsorbent for the enhanced removal of pollutants from feedwater in the presence of other co-existing ions.

The aim of this study was to assess the performance of the novel Ca-doped ferrihydrite for the adsorption of fluoride and to investigate the effect of co-existing ions on the removal process. The proposed research was therefore designed and conducted with five specific objectives: (1) to synthesize Ca-doped ferrihydrite composite adsorbent by co-precipitation method, (2) to determine the characteristics, adsorption behavior, and mechanism of the as-synthesized adsorbent by using extensive characterization methods, (3) to assess the effects of experimental factors affecting the adsorption process, (4) to study the adsorption process by employing the kinetics and isotherm models, and (5) to assess the regeneration ability of Ca-doped ferrihydrite after the removal of fluoride from the water. The findings of the current study provide important insights into the synthesis of the novel adsorbent for the enhanced removal of fluoride from water.

\section{Experimental}




\section{Materials and chemicals}

Ferric nitrate nonahydrate $\left(\mathrm{Fe}\left(\mathrm{NO}_{3}\right)_{3} .9 \mathrm{H}_{2} \mathrm{O}\right)$ and calcium chloride $\left(\mathrm{CaCl}_{2}\right)$ were used for the synthesis of the Ca-doped ferrihydrite. The stock solution for fluoride was prepared by using sodium fluoride (NaF). All the adsorption experiments were performed using ultrapure water, obtained with a Milli-Q system (EPOD, France). The NOM solution was prepared by Suwanee River NOM (SRNOM, batch number 2R101N) and was obtained from the International Humic Substances Society (St. Paul, MN). All other chemicals, including co-existing anions and cations, were bought fro Aladdin Industrial Corporation, Shanghai, China.

\section{Synthesis of Ca-doped ferrihydrite}

Ca-doped ferrihydrite was prepared by using a facile co-precipitation approach. Initially $50 \mathrm{~mL}$ mixed solution containing $1 \mathrm{M}\left(\mathrm{Fe}\left(\mathrm{NO}_{3}\right)_{3} \cdot 9 \mathrm{H}_{2} \mathrm{O}\right)$ and $0.19 \mathrm{M}$ of $\mathrm{CaCl}_{2}$ was prepared. To obtain the desired $\mathrm{pH}$ of 7 , a dropwise $1 \mathrm{M} \mathrm{NaOH}$ was used with constant stirring. The solution was stirred vigorously during the $\mathrm{pH}$ maintenance process. A gel-like precipitate was obtained, and the final volume of that slurry was fixed to $200 \mathrm{~mL}$. The obtained suspension was then stored at room temperature for 24 hours. After that, the precipitates were washed thoroughly with distilled water by using G-4 frit crucible. The remaining material was dried in an air oven for 12 hours at $100^{\circ} \mathrm{C}$. Finally, the obtained material was grinded by using mortar and pestle and stored for further use. Fig. 1 shows the detailed five-step synthesis process of Ca-doped ferrihydrite used in the study.

\section{Characterization of the adsorbent}

Several characterization techniques for Ca-doped ferrihydrite adsorbent were carried out. Functional groups of the as-synthesized Ca-doped ferrihydrite adsorbent were analyzed by Fourier to transform infrared spectroscopy (FTIR) (Nexus670, Nicolet, USA) before and after the adsorption experiment. The morphology and nanostructure of Ca-doped ferrihydrite were investigated by scanning electron microscope (SEM) (HITACHI S-4800). Besides, the crystalline structure of the adsorbent was measured using the X-ray diffraction (XRD) analyzer, D8-Advance, Brucker, Germany). To determine the surface charges of the absorbent, the zeta potential of the Ca-doped ferrihydrite was carried out using the laser Doppler velocimetry technique (Nano-Brook 90 Plus-PALS, Brookhaven, US) in liquid suspension at various $\mathrm{pH}$ levels. The pore volume and specific surface area of Ca-doped ferrihydrite were determined by the nitrogen adsorption isotherm method on an Autosorb-iQ2-C (Quantachrome Instruments, USA). Ion chromatography (IC) and atomic fluorescence spectrophotometry (AFS) were used to quantify the fluoride in the water samples.

\section{Adsorption experiments}

A 100-ppm stock solution of fluoride was prepared by adding $0.221 \mathrm{mg}$ of sodium fluoride (analytical grade) in distilled water. The desired solution for fluoride was obtained by further diluting the stock solution. The $\mathrm{pH}$ of the feed solution was adjusted by adding acid $(0.1 \mathrm{~N} \mathrm{HCl})$ or base $(0.1 \mathrm{M} \mathrm{NaOH})$ 
solution. All the batch experiments were carried out with $50 \mathrm{~mL}$ of water samples at $25 \pm 2{ }^{\circ} \mathrm{C}$ while shaking at 160 revolutions per minute. The effects of different control parameters were studied by using different amounts of adsorbates and adsorbent. After the adsorption experiments, water samples were then filtered immediately by a $0.45 \mu \mathrm{m}$ filter to separate adsorbent particles in the samples. To investigate the effects of different parameters, the operation conditions varied over time while others were kept constant.

Besides, salts such as $\mathrm{NaNO}_{3}, \mathrm{NaCl}, \mathrm{Na}_{2} \mathrm{SO}_{4}, \mathrm{NaHCO}_{3}, \mathrm{Na}_{3} \mathrm{PO}_{4}, \mathrm{CaCl}_{2}, \mathrm{MgCl}_{2}$ and $\mathrm{Na}_{2} \mathrm{CO}_{3}$, were added into the solution to determine the effects of co-existing ions on the adsorption of fluoride from water. The concentration of the co-existing ions in the solution was adjusted between $10 \mathrm{mg} / \mathrm{L}$ to $200 \mathrm{mg} / \mathrm{L}$. The adsorption experiments were performed at $\mathrm{pH} 5.75$, adsorbent dose $300 \mathrm{mg} / \mathrm{L}$, and shaking at $160 \mathrm{rpm}$. The initial concertation of fluoride in the solution was adjusted to $5 \mathrm{mg} / \mathrm{L}$. The final concentration of fluoride was measured after equilibrium time. The adsorption experiments were performed at a different initial period to study adsorption isotherms. The time was varied from 30 to 700 minutes.

The removal efficiency of the as-synthesized adsorbent was determined using eq. (1).

Removal (\%) $=\frac{c_{i}-C_{f}}{c_{i}} \times 100$

where $\mathrm{C}_{\mathrm{i}}$ and $\mathrm{C}_{\mathrm{f}}$ are the initial and final concentration of fluoride, respectively. All adsorption experiments were performed in replicate runs to avoid experimental errors in the results. The relative errors in the calculated data were below $5 \%$ on average.

\section{Regeneration studies}

For the regeneration, Ca-doped ferrihydrite from the solution was collected and soaked in $0.1 \mathrm{M} \mathrm{NaOH}$ solution for a set time. Besides, the effects of time on desorption were investigated, and the concentration fluoride was measured at different time intervals. Desorption efficiency with time was calculated by the total amount of fluoride and the percentage of desorbed fluoride. After the desorption experiment, the adsorbent was collected, activated, and rinsed with ultrapure water, and dried. The obtained adsorbent was used again to study the regeneration of adsorbent. The performance of the regenerated adsorbent was evaluated in five adsorption and desorption cycles.

\section{Results And Discussion}

\section{Characterization of the adsorbent}

The structural morphology and elemental constituents of the as-synthesized Ca-doped ferrihydrite were evaluated by SEM-EDX analysis Fig. 2(a, b). The EDX analysis illustrated that the adsorbent contains $\mathrm{Ca}$ and $\mathrm{Fe}$, which confirmed successful doping of calcium onto the ferrihydrite Fig. 2a. According to the EDX results, the elemental peaks of $\mathrm{Ca}$ and Fe emerged at the energy value of about $3.6 \mathrm{Kev}$ and $7.1 \mathrm{Kev}$ respectively. The elemental percentage of Ca was $0.03 \%$, and Fe was $38.63 \%$ which represents the 
presence of $\mathrm{Ca}$ and Fe on the surface of Ca-doped ferrihydrite. Besides, the SEM results of Ca-doped ferrihydrite adsorbent illustrated that a large microplates type of products was acquired after synthesis Fig. $2 b$. The surface of these large microplates was coarse and connected, that formed a large aggregate.

The XRD analysis of the Ca-doped ferrihydrite was employed to determine the crystalline structure of the

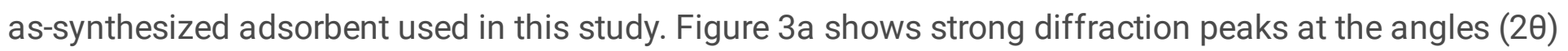
of $38^{\circ}, 44^{\circ}$ and $64^{\circ}$, which are respectively attributed to the planes of (110), (200), and (115) of 6-line ferrihydrite JCPDS (card no: 29-0712). The XRD results further confirmed that the sample is poorly crystalline or amorphous. The results obtained in this study are in good agreement with the published literature and confirmed that the Ca-doped ferrihydrite was 6 line ferrihydrite (Mohapatra et al. 2012).

In addition, the FTIR spectra of Ca-doped ferrihydrite before and after fluoride adsorption is presented in Fig. 3b. The peak at $3357 \mathrm{~cm}^{-1}$ is corresponding to the stretching of surface $\mathrm{OH}$ groups of ferrihydrite and the peak at $1614 \mathrm{~cm}^{-1}$ is therefore associated with the vibration of the water molecule and ferrihydrite. The absorption band at $1383 \mathrm{~cm}^{-1}$ is attributed to carbonates, which might be owing to the poorly crystalline structure and amorphous capture of $\mathrm{CO}_{2}$ from the air ( $\mathrm{Su}$ and Suarez 1997). The band at 1354 and 431 are assigned to hydroxyl bridges of $\mathrm{Fe}-(\mathrm{OH})_{2}-\mathrm{Fe}$, and $\mathrm{Fe}-\mathrm{O}$ bonds, respectively.

Figure 4a displays the pore size distribution and the $\mathrm{N}_{2}$ adsorption-desorption isotherms of the assynthesized Ca-doped ferrihydrite. The BET surface area of the Ca-doped ferrihydrite was determined to be $82.44 \mathrm{~m}^{2} / \mathrm{g}$. The pore volume $\left(0.088 \mathrm{~cm}^{3} / \mathrm{g}\right)$ and the average pore size $(3.515 \mathrm{~nm})$ of the Ca-doped ferrihydrite were calculated by the BJH method. The increased surface area, as well as pore volume and decrease pore size, was observed due to the doping of ferrihydrite with calcium. The high surface area provided more adsorption sites and played a significant role in the adoption of fluoride from the aqueous phase.

Zeta potential measurement was employed to determine the surface charge on the Ca-doped ferrihydrite. The negative zeta potential of adsorbent increased with an increasing the $\mathrm{pH}$ level of the Ca-doped ferrihydrite suspension Fig. $4 \mathrm{~b}$. The point of zero charge $\left(\mathrm{pH}_{\mathrm{zc}}\right)$ of the adsorbent was found to be 6.14 , which means that below this $\mathrm{pH}$ level, the surface of the as-synthesized adsorbent was positively charged. Likewise, at pH 6.14 and higher, the surface of the synthesized adsorbent was negatively charged.

\section{Adsorption experiment}

\section{Effect of initial pH}

The effect of $\mathrm{pH}$ on the removal of fluoride is presented in Fig. $5 \mathrm{a}$. The solution $\mathrm{pH}$ was varied from 3 to 11. At $\mathrm{pH} 3$, the removal of Ca-doped ferrihydrite for fluoride was $90.6 \%$, while increasing the $\mathrm{pH}$ to 5 , the removal of fluoride increased to $97.79 \%$. However, increasing $\mathrm{pH}$ from 5 to 11 , the removal of fluoride gradually reduced to $89 \%$ Fig. $5 \mathrm{a}$. This behavior can be explained on the basis of surface charge of the adsorbent and ionic chemistry of the solution. 
The value of point of zero charge of Ca-doped ferrihydrite in this study was reported about 6.14. The maximum adsorption of fluoride in this study is reported at $\mathrm{pH} 5$ that might be attributed to the strong electrostatic interaction between the fluoride ions and positively charged adsorbent surface. The comparative less removal of fluoride at lower $\mathrm{pH} 3$ is because of less availability of free fluoride ions due to $\mathrm{HF}$ formation. The decrease in the fluoride removal percentage at higher $\mathrm{pH}(\geq 7)$ is attributed to the competition between hydroxyl ions and fluoride to cover the limited adsorption sites on the surface of Cadoped ferrihydrite adsorbent (Mohapatra et al. 2010, 2011).

Hence, these results suggest that electrostatic attraction is not the main reason for the removal of fluoride from water. The removal of fluoride occurs through surface coordination of $\mathrm{Fe}-\mathrm{OH}$ groups. Hence adsorption of fluoride in Ca-doped ferrihydrite is happened due to ion exchange.

\section{Effect of adsorbent dose}

The removal of fluoride was significantly increased up to $85 \%$ by increasing the adsorbent dose to 200 $\mathrm{mg} / \mathrm{L}$ (as presented in Fig. 5b. Further increase of the adsorbent dose from $200 \mathrm{mg} / \mathrm{L}$ to $300 \mathrm{mg} / \mathrm{L}$ improved the removal of fluoride by $98 \%$ Fig. $5 \mathrm{~b}$. These results showed that there was an immediate and remarkable increase in the percentage removal of fluoride when the dose range increased from $100 \mathrm{mg} / \mathrm{L}$ to $300 \mathrm{mg} / \mathrm{L}$. The enhanced removal of fluoride is owing to the increased number of active surface sites available on adsorbent for the adsorption of fluoride ions (Bhaumik et al. 2011). Also, the removal \% of fluoride remained the same when the dose range was increased to $400,600,800$, and $1000 \mathrm{mg} / \mathrm{L}$. This is most probably due to saturation of the active adsorption sites on the surface of the adsorbent. Therefore, no further increase in the removal of fluoride was reported (Swain et al. 2012; Srivastav et al. 2013).

\section{Effect of co-existing ions}

The effects of co-existing ions on the removal of fluoride for the same adsorption sites were investigated. Co-existing ions such as phosphate $\left(\mathrm{PO}_{4}{ }^{2-}\right)$, sulfate $\left(\mathrm{SO}_{4}{ }^{2-}\right)$, nitrate $\left(\mathrm{NO}_{3}{ }^{-}\right)$, chloride $\left(\mathrm{Cl}^{-}\right)$, carbonate ions $\left(\mathrm{CO}_{3}{ }^{2-}\right)$ and bicarbonate $\left(\mathrm{HCO}_{3}{ }^{-}\right)$, and cations such as calcium $\left(\mathrm{Ca}^{2+}\right)$ and magnesium $\left(\mathrm{Mg}^{2+}\right)$ were added to the feed solution before the adsorption experiment. Besides, the concentration of co-existing ions was varied in the range from $10 \mathrm{mg} / \mathrm{L}$ to $200 \mathrm{mg} / \mathrm{L}$. The presence of $\mathrm{SO}_{4}{ }^{2-}, \mathrm{NO}_{3}{ }^{-}$and $\mathrm{Cl}^{-}$exhibited no detrimental effects on the removal of fluoride from water; however, the removal of fluoride slightly reduced when the concentration of $\mathrm{SO}_{4}{ }^{2-}, \mathrm{NO}_{3}{ }^{-}$and $\mathrm{Cl}^{-}$ions reaches up to $200 \mathrm{mg} / \mathrm{L} \mathrm{Fig.} \mathrm{6a.} \mathrm{The} \mathrm{same}$ results were also reported by authors in the past for different adsorbents (Zhu et al. 2015; Zhang et al. 2016). Higher concentrations of $\mathrm{PO}_{4}{ }^{2-}, \mathrm{HCO}_{3}{ }^{-}$and $\mathrm{CO}_{3}{ }^{2-}$ have significant effects on the adsorption rate of fluoride. At lower concentrations, these ions have no considerable effects on the fluoride removal by Ca-doped ferrihydrite. The results suggest that the low or almost none removal of fluoride at high concentration of $\mathrm{PO}_{4}{ }^{2-}, \mathrm{HCO}_{3}{ }^{-}$and $\mathrm{CO}_{3}{ }^{2-}$ is because of the competitions of these ions with fluoride on the same adsorption sites by Ca-doped ferrihydrite, which forms complexes with the hydroxyl group of the adsorbent and prevent any possible interaction of fluoride ions with the as-synthesized adsorbent. 
Increased removal of fluoride was obtained when the feed solution contained cations such as $\mathrm{Mg}^{2+}$ and $\mathrm{Ca}^{2+}$ ions (as observed in Fig. 6b. The enhanced removal is accredited to the formation of insoluble $\mathrm{CaF}_{2}$ and $\mathrm{MgF}_{2}$ (Chen et al. 2010). Similar effects of these cations on the removal fluoride through the adsorption process are also reported in previous studies (Kagne et al. 2008; Maliyekkal et al. 2010).

\section{Effect of NOM}

The presence of NOM in water influence the removal efficiency of fluoride during adsorption. Therefore, the influence of NOM on the removal of fluoride is indeed important for large scale applications of the assynthesized Ca-doped ferrihydrite for water treatment. The presence of NOM in all the studied concentrations ranged from $5 \mathrm{mg} / \mathrm{L}$ to $25 \mathrm{mg} / \mathrm{L}$. It can be seen in Fig. 7a, the Ca-doped ferrihydrite removed about $95 \%$ of fluoride from the aqueous solution in the presence of $5 \mathrm{mg} / \mathrm{L}$ of NOM. A gradual decline (i.e. about $5 \%$ ) in the removal of fluoride was seen by increasing the NOM concentration to $25 \mathrm{mg}$ /L Fig. 7a. In addition, the influence of contact time of NOM on the removal of fluoride was investigated from 1 hour to 12 hours. The removal of fluoride in the first 1 hour was about $90 \%$, while after 2 hours of contact time the removal of fluoride by Ca-doped ferrihydrite suddenly increased to $94 \%$ Fig. $7 \mathrm{~b}$. After two hours, the removal percentage of fluoride by Ca-doped ferrihydrite was remained constant at about $95 \%$ until 12 hours Fig. 7b. Overall, the results demonstrate that the contact time has no substantial effects on the removal of fluoride in the presence of NOM by Ca-doped ferrihydrite. A Ca-doped ferrihydrite is a form of iron base adsorbents, and the removal efficiency of Ca-doped ferrihydrite is not significantly affecting by the presence of organic matter (Tang et al. 2014). Therefore, the results suggest that NOM did not complete with fluoride during the adsorption process by the Ca-doped ferrihydrite, and the novel adsorbent has the application potential in real water treatment.

\section{Effect of temperature}

The effects of temperature on the removal of fluoride by Ca-doped ferrihydrite was investigated. The adsorption experiments were out at different pre-defined temperatures such as $20,25,30,40$, and $45^{\circ} \mathrm{C}$, as depicted in Fig. 8a. A small increase in temperature from $20^{\circ} \mathrm{C}$ to $25^{\circ} \mathrm{C}$ has resulted in an increase in the removal of fluoride from $90-94 \%$. However, a slight increase from $94-98 \%$ in the removal of fluoride was observed while increasing the temperature from $25^{\circ} \mathrm{C}$ to $45^{\circ} \mathrm{C}$. The increase in the removal efficiency of fluoride by Ca-doped ferrihydrite with temperature is accredited to the increase in the kinetic energy of the fluoride molecules. The similar nature of fluoride adsorption was also reported for iron-mixed oxides particles (Biswas et al. 2009). The findings from this study suggest that the adsorption process of fluoride by Ca-doped ferrihydrite was endothermic.

\section{Adsorption isotherms and kinetics studies}

The adsorption kinetics of fluoride onto the as-synthesized adsorbent is of great interest for its application in water treatment. The adsorption of fluoride was carried out at a range of contact time from 30 mins to 12 hours Fig. 8b. In addition, the adsorption of fluoride in the first 30 minutes was $85 \%$ and 
then dramatically increased to about $98 \%$ after 2 hours of contact time of the adsorbent. However, the removal of fluoride remained at $98 \%$ for the rest of the contact time (as shown in Fig. 8b.

The following equations (2-3) represents the Langmuir, and Freundlich isotherm and (4-5) represents the pseudo-first order (McKay and McConvey, I.F. 1981; Ho and Mckay 1998) and second order (Ho and McKay 1999) kinetic models, respectively.

$$
\begin{aligned}
& \frac{1}{q_{e}}=\frac{1}{q_{\max }}+\left(\frac{1}{q_{\max } \mathrm{K}_{\mathrm{L}}}\right) \frac{1}{\mathrm{C}_{\mathrm{e}}} \\
& q_{e}=K_{f} C_{e}^{1 / n} \\
& \ln \left(q_{e}-q_{t}\right)=\ln q_{e}-k_{1} t \\
& \frac{\boldsymbol{t}}{\boldsymbol{q}_{\boldsymbol{t}}}=\frac{\mathbf{1}}{\boldsymbol{k}_{2} q_{e}^{2}}+\frac{\boldsymbol{t}}{\boldsymbol{q}_{e}}
\end{aligned}
$$

where $\mathrm{q}_{\mathrm{e}}$ and $\mathrm{q}_{\max }$ are the equilibrium and maximum adsorption capacity of the Ca-doped ferrihydrite $(\mathrm{mg} / \mathrm{g})$, respectively, while $\mathrm{C}_{e}$ denotes the concentration of fluoride in the solution $(\mathrm{mg} / \mathrm{L})$ at equilibrium,

and $\mathrm{K}_{\mathrm{L}}$ is constant. Furthermore, $\mathrm{K}_{\mathrm{f}}$ denotes the Freundlich isotherm model constant that is an indication of the extent of adsorption and $1 / \mathrm{n}$ shows the intensity of adsorption. Furthermore, $\mathrm{q}_{\mathrm{e}}(\mathrm{mg} / \mathrm{g})$ and $\mathrm{q}_{\mathrm{t}}$ $(\mathrm{mg} / \mathrm{g})$ are the adsorption capacity of Ca-doped ferrihydrite at equilibrium and time $\mathrm{t}(\mathrm{min})$, respectively, and $\mathrm{k}_{2}(\mathrm{~g} / \mathrm{mg} / \mathrm{min})$ is a rate constant of the pseudo-second-order.

The underlying mechanism of the as-synthesized adsorbent and the rate of fluoride adsorption on the surface of the Ca-doped ferrihydrite was studied using the pseudo-second order kinetic model. The pseudo-second kinetic model assumes that the adsorption mechanism for contaminants is chemisorption and involves the exchange of electrons between the adsorbent and fluoride ions (Ali et al. 2018; Mohammed et al. 2019).

\section{Adsorption isotherms}

Modelling the adsorption data is essential for the optimization of adsorbent utilization and explaining the interactive nature, adsorption mechanisms, and performance of the adsorbent. The most frequently used isotherm models are the Langmuir and Freundlich isotherms (Mohammed et al. 2019). Langmuir model (1918) has characterized the homogeneous, monolayer, and identical energies over a specific number of adsorption sites. In this study, two of the isotherms, Freundlich and Langmuir, have been employed to the adsorption input to inspect its reliability. Factors for the Langmuir model are estimated from the plot for $\mathrm{C}_{\mathrm{e}} / \mathrm{q}_{\mathrm{e}}$ versus $\mathrm{C}_{\mathrm{e}}$, and the Freundlich model is calculated from the plot $\log$ of $\mathrm{q}_{\mathrm{e}}$ versus $\log \mathrm{C}_{\mathrm{e}}$ (as shown in Fig. $9(\mathrm{a}, \mathrm{b})$. Based on the correlation coefficient values, experimental data for the adsorption of fluoride best fitted to the Langmuir Model $\left(R^{2}=0.99\right)$ compared to the Freundlich isotherm model $\left(R^{2}=0.97\right)$. The relative parameters corresponding to the fitting results of Langmuir isotherm and Freundlich isotherm 
models are shown in Table 1. Langmuir model shows single layer adsorption having an $\mathrm{R}^{2}$ value of 0.99 while comparing the Freundlich isotherm with a deprived $R^{2}$ value of 0.97 follows multilayer adsorption. From these results, we can conclude that the reaction was chemisorption and suited better to the Langmuir model. Therefore, the possible mechanism was the exchange of ions on the active surface sites of the as-synthesized adsorbent.

Table 1

Adsorption isotherm parameters

\begin{tabular}{|llll|}
\hline Langmuir & \multicolumn{3}{l|}{ Freundlich } \\
\hline $\mathbf{q}_{\mathbf{m}}(\mathrm{mg} / \mathrm{g})$ & 53.21 & $\mathbf{1 / n}$ & 0.503 \\
\hline $\mathrm{K}_{\mathrm{L}}(\mathrm{L} / \mathrm{mol})$ & 0.045 & $\mathrm{~K}_{\mathrm{f}}\left(\mathrm{mg} \mathrm{g}^{-1}\right)\left(\mathrm{L} \mathrm{mg}^{-1}\right)^{1 / n}$ & 6.87 \\
$\mathrm{R}^{2}$ & 0.993 & $\mathrm{R}^{2}$ & 0.975 \\
\hline
\end{tabular}

\section{Adsorption kinetics}

To better understand the adsorption process and the underlying mechanisms, kinetic models such as the pseudo-first and pseudo-second order were applied to illustrate the kinetics of the adsorption of fluoride. In addition, the correlation coefficients and kinetic parameters were determined from the linear log plots such as $\left(q_{e}-q_{t}\right)$ versus $t$ and $t / q_{t}$ versus $t$, for the pseudo-first and pseudo-second order kinetics Fig. 10 $(a, b)$. The pseudo-second order model well fitted with the adsorption results based on $\mathrm{R}^{2}$ values of 0.99 , indicating that the chemisorption of fluoride on the active surface sites of the as-synthesized adsorbent occurred due to the exchange of ions. The calculated $\mathrm{q}_{\mathrm{e}}$ values were estimated from the pseudo-second order was very close to the value obtained from the adsorption experiments Table 2 . Thus, the pseudosecond order kinetic model is an appropriate model to describe the adsorption of fluoride pollutants onto Ca-doped ferrihydrite. This also confirms that the removal of fluoride best fitted the Langmuir isotherm model assumptions of the monolayer adsorption by the novel Ca-doped ferrihydrite. This clearly shows that chemisorption is the dominant mechanism for the removal of fluoride by the Ca-doped ferrihydrite.

Table 2

Kinetic models parameters

\begin{tabular}{|c|c|c|c|c|}
\hline \multicolumn{5}{|c|}{ Pseudo-first order kinetic model } \\
\hline $\mathrm{C}_{0}(\mathrm{mg} / \mathrm{l})$ & $q_{e, \exp }(m g / g)$ & $k_{1}\left(\min ^{-1}\right)$ & $\mathbf{R}^{2}$ & \\
\hline 7 & 12.34 & $6.909^{\times 10-3}$ & 0.7547 & \\
\hline \multicolumn{5}{|c|}{ Pseudo-second order kinetic model } \\
\hline $\mathrm{q}_{\mathrm{e}, \mathrm{cal}}(\mathrm{mg} / \mathrm{g})$ & $\mathrm{R}^{2}$ & $q_{e, \exp }(m g / g)$ & $\mathrm{C}_{0}(\mathrm{mg} / \mathrm{L})$ & $\mathrm{k}_{2}\left(\mathrm{~g} \mathrm{mg}^{-1} \mathrm{~min}^{-1}\right)$ \\
\hline 15.62 & 0.999 & 15.15 & 7 & 0.021 \\
\hline
\end{tabular}




\section{Adsorption mechanism}

The proposed adsorption mechanism of fluoride by the Ca-doped ferrihydrite is depicted in Fig. 11. The major mechanisms involved in the adsorption of fluoride onto the surface of Ca-doped ferrihydrite are electrostatic interaction, physical adsorption and $\pi-\pi$ interactions. Electrostatic interactions are dominant at $\mathrm{pH}$ below $\mathrm{pHzc}$ (6.14) due to attraction of $\mathrm{F}^{-}$ions towards the positively charged Ca-doped ferrihydrite surface.

\section{Regeneration of Ca-doped ferrihydrite}

To determine the stability and reusability of adsorbent, fast, and effective regeneration after adsorption is necessary, which makes the adsorption process more convenient, sustainable, and cost-effective (Biswas et al. 2009). Therefore, the adsorption and desorption studies of fluoride for five consecutive cycles were conducted to determine the regeneration capability of Ca-doped ferrihydrite Fig. 12 . We used a $0.1 \mathrm{M}$ $\mathrm{NaOH}$ solution for the desorption of fluoride from the surface of Ca-doped ferrihydrite. The removal efficiency of Ca-doped ferrihydrite for fluoride was slightly declined with the regeneration of the adsorbent, as shown in Fig. 12. After the first cycle of regeneration, the removal efficiency of Ca-doped ferrihydrite towards fluoride was $91 \%$. After the fifth cycle, the removal percentage gradually declined to $80 \%$ Fig. 12 , which is still promising for the removal of fluoride from the feed water. Therefore, these results suggest that Ca-doped ferrihydrite can be used for the long-term adsorption of fluoride from drinking water without any decrease in adsorption efficiency.

\section{Comparison of adsorption capacity with other adsorbents}

Table 3 provides a comparative analysis of the various adsorbents for the adsorption of fluoride. As evident from the table, the as-synthesized Ca-doped ferrihydrite adsorbent exhibited a higher adsorption capacity for fluoride as compared to most of the adsorbents reported in the literature. This confirms that the novel Ca-doped ferrihydrite has a promising potential to be employed for the decontamination of fluoride-containing water. 
Table 3

Comparison of adsorption capacities of various iron-based adsorbents for fluoride.

\begin{tabular}{|lll|}
\hline Adsorbents & $\begin{array}{l}\text { Adsorption } \\
\text { Capacity } \\
(\mathbf{m g} / \mathbf{g})\end{array}$ & Reference \\
\hline Ferric hydroxide & 7.0 & (Kumar et al. 2009) \\
\hline Boehmite & 2.06 & $\begin{array}{l}\text { (Jiménez-Becerril et al. } \\
\text { 2012) }\end{array}$ \\
\hline Neodymium-modified chitosan & 22.38 & (Yao et al. 2009) \\
\hline Activated quart & 1.16 & (Fan et al. 2003) \\
\hline Sulfate-doped Fe $\mathrm{O}_{4} / \mathrm{Al}_{2} \mathrm{O}_{3}$ & 70.4 & (Chai et al. 2013) \\
\hline Hydrous ferric oxide & 16.5 & (Dey et al. 2004) \\
\hline PPy/Fe $\mathrm{O}_{4}$ & 22.3 & (Biswas et al. 2010) \\
\hline 2-Line ferrihydrite & 23.89 & (Mohammed et al. 2019) \\
\hline Calcite & 0.39 & (Mohammed et al. 2019) \\
\hline Iron(III)-tin(IV) mixed oxide & 10.47 & (Biswas et al. 2009) \\
\hline CTAB assisted mixed iron oxide & 40.4 & (Mohapatra et al. 2011) \\
\hline Hydrated Fe(III)-Al(III)-Cr(III) ternary mixed oxide & 31.9 & (Biswas et al. 2010) \\
\hline $\begin{array}{l}\text { Zinc-magnesium-aluminum ternary oxide } \\
\text { microspheres }\end{array}$ & 84.24 & (Gao et al. 2020) \\
\hline Ce-AlOOH with oxalic acid & 90 & (Tao et al. 2020) \\
\hline Ca-doped ferrihydrite & 53.21 & This study \\
\hline
\end{tabular}

\section{Conclusion}

A novel Ca-doped ferrihydrite adsorbent was successfully synthesized and evaluated under controlled environmental conditions for the removal of fluoride from aqueous solution. The prepared adsorbent exhibited tremendous adsorption potential for the uptake of fluoride from water. The effects of interfering anions and natural organic matter was negligible at low concentrations, while the presence of cations enhanced the removal of fluoride. The results obtained in this study confirmed that the adsorption of fluoride by Ca-doped ferrihydrite was endothermic in nature. The prepared adsorbent can be regenerated easily and can be reused in multiple cycles for the uptake of fluoride from water. The novel Ca-doped ferrihydrite adsorbent holds a tremendous practical application potential in wastewater treatment.

\section{Declarations}




\section{Acknowledgement}

The authors would like to thank Dr. Yu Yang from the School of Environment, Beijing Normal University, China for supervising the first author throughout his study. In addition, Mr. Khalil Ahmad, Izaz Ali Shah, and Sharafat Ali were recipients of the Chinese Government Scholarship that supported their stay at Beijing Normal University, where this study was performed.

\section{Funding}

This research was financially supported by the department of environmental engineering, School of Environment, Beijing Normal University, Beijing, China.

\section{Author contribution}

Khalil Ahmad: Research design, methodology, formal analysis, investigation, writing original draft, Izaz Ali Shah: writing review and editing, Sharafat Ali: investigation, writing original draft, writing review and editing, Muhammad Tariq Khan methodology, formal analysis, investigation, writing original draft, Muhammad Bilal Ahmed Qureshi review and editing, Syed Hassan Ali Shah: writing-review and editing, Asmat Ali: review and editing in isotherm model kinetics study, formatting, Wajid Rashid: Review and editing, Hifza Nayab Gul: help in figures and writing

\section{Competing interests}

The authors declare that they have no competing interest

\section{Consent to publish}

The authors agree to publish this article in the Environmental Science and Pollution Research

Availability of data and materials the datasets used in this study are available from the master study research.

\section{Consent to participate}

We confirm that the manuscript has been read and approved by all named authors and that there are no other persons who satisfied the criteria for authorship but are not listed. We further confirm that the order of authors listed in the manuscript has been approved by all of us.

\section{Ethical approval}

Not Applicable.

\section{Availability of data and materials}

Not Applicable. 


\section{References}

1. Aamir A, Basim A, Ihsanullah, et al (2016) Benzene removal by iron oxide nanoparticle decorated carbon nanotubes. J Nanomater

2. Abdelgawad AM, Watanabe K, Takeuchi S, Mizuno T (2009) The origin of fluoride-rich groundwater in Mizunami area, Japan-Mineralogy and geochemistry implications. Eng Geol 108:76-85

3. Ali A, Bilal M, Khan R, et al (2018) Ultrasound-assisted adsorption of phenol from aqueous solution by using spent black tea leaves. Environ Sci Pollut Res 25:22920-22930

4. Ali H, Khan E, llahi I (2019) Environmental chemistry and ecotoxicology of hazardous heavy metals: environmental persistence, toxicity, and bioaccumulation. J Chem 2019:

5. Amini M, Mueller K, Abbaspour KC, et al (2008) Statistical modeling of global geogenic fluoride contamination in groundwaters. Environ Sci Technol 42:3662-3668

6. Asmaly HA, Ihsanullah, Abussaud B, et al (2016) Adsorption of phenol on aluminum oxide impregnated fly ash. Desalin Water Treat 57:6801-6808.

https://doi.org/10.1080/19443994.2015.1010238

7. Balasubramani K, Sivarajasekar N, Naushad M (2020) Effective adsorption of antidiabetic pharmaceutical (metformin) from aqueous medium using graphene oxide nanoparticles: Equilibrium and statistical modelling. J Mol Liq 301:112426

8. Banks D, Reimann C, Røyset O, et al (1995) Natural concentrations of major and trace elements in some Norwegian bedrock groundwaters. Appl Geochemistry 10:1-16

9. Bhatnagar A, Kumar E, Sillanpää M (2011) Fluoride removal from water by adsorption-a review. Chem Eng J 171:811-840

10. Bhaumik M, Leswifi TY, Maity A, et al (2011) Removal of fluoride from aqueous solution by polypyrrole/Fe304 magnetic nanocomposite. J Hazard Mater 186:150-159

11. Biswas K, Gupta K, Ghosh UC (2009) Adsorption of fluoride by hydrous iron (III)-tin (IV) bimetal mixed oxide from the aqueous solutions. Chem Eng J 149:196-206

12. Biswas K, Gupta K, Goswami A, Ghosh UC (2010) Fluoride removal efficiency from aqueous solution by synthetic iron (III)-aluminum (III) - chromium (III) ternary mixed oxide. Desalination 255:44-51

13. Blagojević SD, Jakovljević MD, Radulović M (2002) Content of fluorine in soils in the vicinity of aluminium plant in Podgorica. J Agric Sci 47:1-8

14. Brunson LR, Sabatini DA (2009) An evaluation of fish bone char as an appropriate arsenic and fluoride removal technology for emerging regions. Environ Eng Sci 26:1777-1784

15. Cai H, Chen G, Peng C, et al (2015) Removal of fluoride from drinking water using tea waste loaded with Al/Fe oxides: A novel, safe and efficient biosorbent. Appl Surf Sci 328:34-44

16. Çengeloğlu Y, Kır E, Ersöz M (2002) Removal of fluoride from aqueous solution by using red mud. Sep Purif Technol 28:81-86 
17. Chai L, Wang Y, Zhao N, et al (2013) Sulfate-doped Fe304/Al2O3 nanoparticles as a novel adsorbent for fluoride removal from drinking water. Water Res 47:4040-4049

18. Chen N, Zhang Z, Feng C, et al (2010) An excellent fluoride sorption behavior of ceramic adsorbent. J Hazard Mater 183:460-465

19. Dey S, Goswami S, Ghosh UC (2004) Hydrous ferric oxide (HFO)-a scavenger for fluoride from contaminated water. Water Air Soil Pollut 158:311-323

20. Dong S, Wang Y (2016) Characterization and adsorption properties of a lanthanum-loaded magnetic cationic hydrogel composite for fluoride removal. Water Res 88:852-860. https://doi.org/https://doi.org/10.1016/j.watres.2015.11.013

21. Drouiche N, Djouadi-Belkada F, Ouslimane T, et al (2013) Photovoltaic solar cells industry wastewater treatment. Desalin Water Treat 51:5965-5973

22. Fan X, Parker DJ, Smith MD (2003) Adsorption kinetics of fluoride on low cost materials. Water Res 37:4929-4937

23. Gao M, Wang W, Yang H, Ye B-C (2020) Efficient removal of fluoride from aqueous solutions using 3D flower-like hierarchical zinc-magnesium-aluminum ternary oxide microspheres. Chem Eng J 380:122459. https://doi.org/https://doi.org/10.1016/j.cej.2019.122459

24. Gomez MA, Hendry MJ, Hossain A, et al (2013) Abiotic reduction of 2-line ferrihydrite: effects on adsorbed arsenate, molybdate, and nickel. RSC Adv 3:25812-25822

25. Habuda-Stanić M, Ravančić ME, Flanagan A (2014) A review on adsorption of fluoride from aqueous solution. Materials (Basel) 7:6317-6366

26. He J, Zhang K, Wu S, et al (2016) Performance of novel hydroxyapatite nanowires in treatment of fluoride contaminated water. J Hazard Mater 303:119-130. https://doi.org/https://doi.org/10.1016/j.jhazmat.2015.10.028

27. Ho YS, Mckay G (1998) Kinetic models for the sorption of dye from aqueous solution by wood. Process Saf Environ Prot 76:183-191. https://doi.org/https://doi.org/10.1205/095758298529326

28. Ho YS, McKay G (1999) Pseudo-second order model for sorption processes. Process Biochem 34:451-465. https://doi.org/https://doi.org/10.1016/S0032-9592(98)00112-5

29. Hu CY, Lo SL, Kuan WH, Lee YD (2005) Removal of fluoride from semiconductor wastewater by electrocoagulation-flotation. Water Res 39:895-901

30. Ihsanullah, Abbas A, Al-Amer AM, et al (2016a) Heavy metal removal from aqueous solution by advanced carbon nanotubes: Critical review of adsorption applications. Sep Purif Technol 157:141161. https://doi.org/10.1016/j.seppur.2015.11.039

31. Ihsanullah, Al-khaldi FA, Abu-sharkh B, et al (2016b) Effect of acid modification on adsorption of hexavalent chromium $(\mathrm{Cr}(\mathrm{VI}))$ from aqueous solution by activated carbon and carbon nanotubes. Desalin Water Treat 57:7232-7244. https://doi.org/10.1080/19443994.2015.1021847

32. Ihsanullah, Al-Khaldi FA, Abusharkh B, et al (2015) Adsorptive removal of cadmium(II) ions from liquid phase using acid modified carbon-based adsorbents. J Mol Liq 204:255-263. 
https://doi.org/10.1016/j.molliq.2015.01.033

33. Ihsanullah I (2020) MXenes (two-dimensional metal carbides) as emerging nanomaterials for water purification: Progress, challenges and prospects. Chem Eng J 388:124340.

https://doi.org/10.1016/j.cej.2020.124340

34. Islam M, Patel RK (2007) Evaluation of removal efficiency of fluoride from aqueous solution using quick lime. J Hazard Mater 143:303-310

35. Jadhav S V, Bringas E, Yadav GD, et al (2015) Arsenic and fluoride contaminated groundwaters: a review of current technologies for contaminants removal. J Environ Manage 162:306-325

36. Jain S, Jayaram R V (2009) Removal of fluoride from contaminated drinking water using unmodified and aluminium hydroxide impregnated blue lime stone waste. Sep Sci Technol 44:1436-1451

37. Jiménez-Becerril J, Solache-Ríos M, García-Sosa I (2012) Fluoride removal from aqueous solutions by boehmite. Water, Air, Soil Pollut 223:1073-1078

38. Kagne S, Jagtap S, Dhawade P, et al (2008) Hydrated cement: a promising adsorbent for the removal of fluoride from aqueous solution. J Hazard Mater 154:88-95

39. Kang D, Yu X, Ge M (2017) Morphology-dependent properties and adsorption performance of CeO2 for fluoride removal. Chem Eng J 330:36-43.

https://doi.org/https://doi.org/10.1016/j.cej.2017.07.140

40. Karthikeyan G, Shunmugasundarraj A (2000) Isopleth mapping and in-situ fluoride dependence on water quality in the Krishnagiri block of Tamil Nadu in South India. Fluoride 33:121-127

41. Khalid A, Zubair M, Ihsanullah (2018) A comparative study on the adsorption of Eriochrome Black T Dye from aqueous solution on graphene and acid-modified graphene. Arab J Sci Eng 43:2167-2179. https://doi.org/10.1007/s13369-017-2543-x

42. Khatibikamal V, Torabian A, Janpoor F, Hoshyaripour G (2010) Fluoride removal from industrial wastewater using electrocoagulation and its adsorption kinetics. J Hazard Mater 179:276-280

43. Kumar E, Bhatnagar A, Ji M, et al (2009) Defluoridation from aqueous solutions by granular ferric hydroxide (GFH). Water Res 43:490-498

44. Liu Z, Lu Y, Duan X (2020) Cr(VI) removal from water by magnetic ferrihydrite: adsorption performance and adsorbent characterization. Int J Environ Anal Chem 1-15. https://doi.org/10.1080/03067319.2020.1779246

45. Maliyekkal SM, Antony KR, Pradeep T (2010) High yield combustion synthesis of nanomagnesia and its application for fluoride removal. Sci Total Environ 408:2273-2282

46. McKay G, McConvey, I.F. (1981) Zur theorie der sogenannten adsorption gelöster stoffe. J Chem Tech Biotech 31:401-408

47. Mohammed BB, Yamni K, Tijani N, et al (2019) Adsorptive removal of phenol using faujasite-type $Y$ zeolite: Adsorption isotherms, kinetics and grand canonical Monte Carlo simulation studies. J Mol Liq 296:111997 
48. Mohapatra M, Hariprasad D, Mohapatra L, et al (2012) Mg-doped nano ferrihydrite-A new adsorbent for fluoride removal from aqueous solutions. Appl Surf Sci 258:4228-4236

49. Mohapatra M, Rout K, Gupta SK, et al (2010) Facile synthesis of additive-assisted nano goethite powder and its application for fluoride remediation. J Nanoparticle Res 12:681-686

50. Mohapatra M, Rout K, Singh P, et al (2011) Fluoride adsorption studies on mixed-phase nano iron oxides prepared by surfactant mediation-precipitation technique. J Hazard Mater 186:1751-1757

51. Mourad NM, Sharshar T, Elnimr T, Mousa MA (2009) Radioactivity and fluoride contamination derived from a phosphate fertilizer plant in Egypt. Appl Radiat Isot 67:1259-1268

52. Naushad M (2014) Surfactant assisted nano-composite cation exchanger: Development, characterization and applications for the removal of toxic $\mathrm{Pb} 2+$ from aqueous medium. Chem Eng $\mathrm{J}$ 235:100-108

53. Nur T, Loganathan P, Nguyen TC, et al (2014) Batch and column adsorption and desorption of fluoride using hydrous ferric oxide: Solution chemistry and modeling. Chem Eng J 247:93-102

54. Parmar HS, Patel JB, Sudhakar P, Koshy VJ (2006) Removal of fluoride from water with powdered corn cobs. J Environ Sci Eng 48:135-138

55. Pillai P, Dharaskar S, Pandian S, Panchal H (2020) Overview of fluoride removal from water using separation techniques. Environ Technol Innov 101246.

https://doi.org/https://doi.org/10.1016/j.eti.2020.101246

56. Ponsot I, Falcone R, Bernardo E (2013) Stabilization of fluorine-containing industrial waste by production of sintered glass-ceramics. Ceram Int 39:6907-6915

57. Rafique T, Naseem S, Bhanger MI, Usmani TH (2008) Fluoride ion contamination in the groundwater of Mithi sub-district, the Thar Desert, Pakistan. Environ Geol 56:317-326

58. Rout K, Mohapatra M, Anand S (2012) 2-Line ferrihydrite: synthesis, characterization and its adsorption behaviour for removal of $\mathrm{Pb}$ (II), $\mathrm{Cd}$ (II), $\mathrm{Cu}$ (II) and $\mathrm{Zn}$ (II) from aqueous solutions. Dalt Trans 41:3302-3312

59. santé O mondiale de la, Zdrowia ŚO, Organization WH, Staff WHO (2004) Guidelines for drinkingwater quality. World Health Organization

60. Shen F, Chen X, Gao P, Chen G (2003) Electrochemical removal of fluoride ions from industrial wastewater. Chem Eng Sci 58:987-993

61. Srivastav AL, Singh PK, Srivastava V, Sharma YC (2013) Application of a new adsorbent for fluoride removal from aqueous solutions. J Hazard Mater 263:342-352

62. Su C, Suarez DL (1997) In situ infrared speciation of adsorbed carbonate on aluminum and iron oxides. Clays Clay Miner 45:814-825

63. Subba Rao N (2003) Groundwater quality: focus on fluoride concentration in rural parts of Guntur district, Andhra Pradesh, India. Hydrol Sci J 48:835-847

64. Swain SK, Mishra S, Patnaik T, et al (2012) Fluoride removal performance of a new hybrid sorbent of $\mathrm{Zr}$ (IV)-ethylenediamine. Chem Eng J 184:72-81 
65. Tang W-W, Zeng G-M, Gong J-L, et al (2014) Impact of humic/fulvic acid on the removal of heavy metals from aqueous solutions using nanomaterials: a review. Sci Total Environ 468:1014-1027

66. Tang Y, Wang J, Gao N (2010) Characteristics and model studies for fluoride and arsenic adsorption on goethite. J Environ Sci 22:1689-1694

67. Tao W, Zhong H, Pan X, et al (2020) Removal of fluoride from wastewater solution using Ce-AlOOH with oxalic acid as modification. J Hazard Mater 384:121373. https://doi.org/https://doi.org/10.1016/j.jhazmat.2019.121373

68. Thompson T, Fawell J, Kunikane S, et al (2007) Chemical safety of drinking water: assessing priorities for risk management. World Health Organization

69. Turner BD, Binning P, Stipp SLS (2005) Fluoride removal by calcite: evidence for fluorite precipitation and surface adsorption. Environ Sci Technol 39:9561-9568

70. Van Eynde E, Mendez JC, Hiemstra T, Comans RNJ (2020) Boron Adsorption to Ferrihydrite with Implications for Surface Speciation in Soils: Experiments and Modeling. ACS Earth Sp Chem 4:1269-1280. https://doi.org/10.1021/acsearthspacechem.0c00078

71. Warmadewanthi B, Liu JC (2009) Selective separation of phosphate and fluoride from semiconductor wastewater. Water Sci Technol 59:2047-2053

72. Yao R, Meng F, Zhang L, et al (2009) Defluoridation of water using neodymium-modified chitosan. J Hazard Mater 165:454-460

73. Zhang C, Li Y, Wang T-J, et al (2016) Adsorption of drinking water fluoride on a micron-sized magnetic Fe304@ Fe-Ti composite adsorbent. Appl Surf Sci 363:507-515

74. Zhu B-S, Jia Y, Jin Z, et al (2015) A facile precipitation synthesis of mesoporous 2-line ferrihydrite with good fluoride removal properties. RSC Adv 5:84389-84397

75. Zubair M, Ihsanullah I, Abdul Aziz H, et al (2020) Sustainable wastewater treatment by biochar/layered double hydroxide composites: Progress, challenges, and outlook. Bioresour Technol 319:124128

\section{Figures}




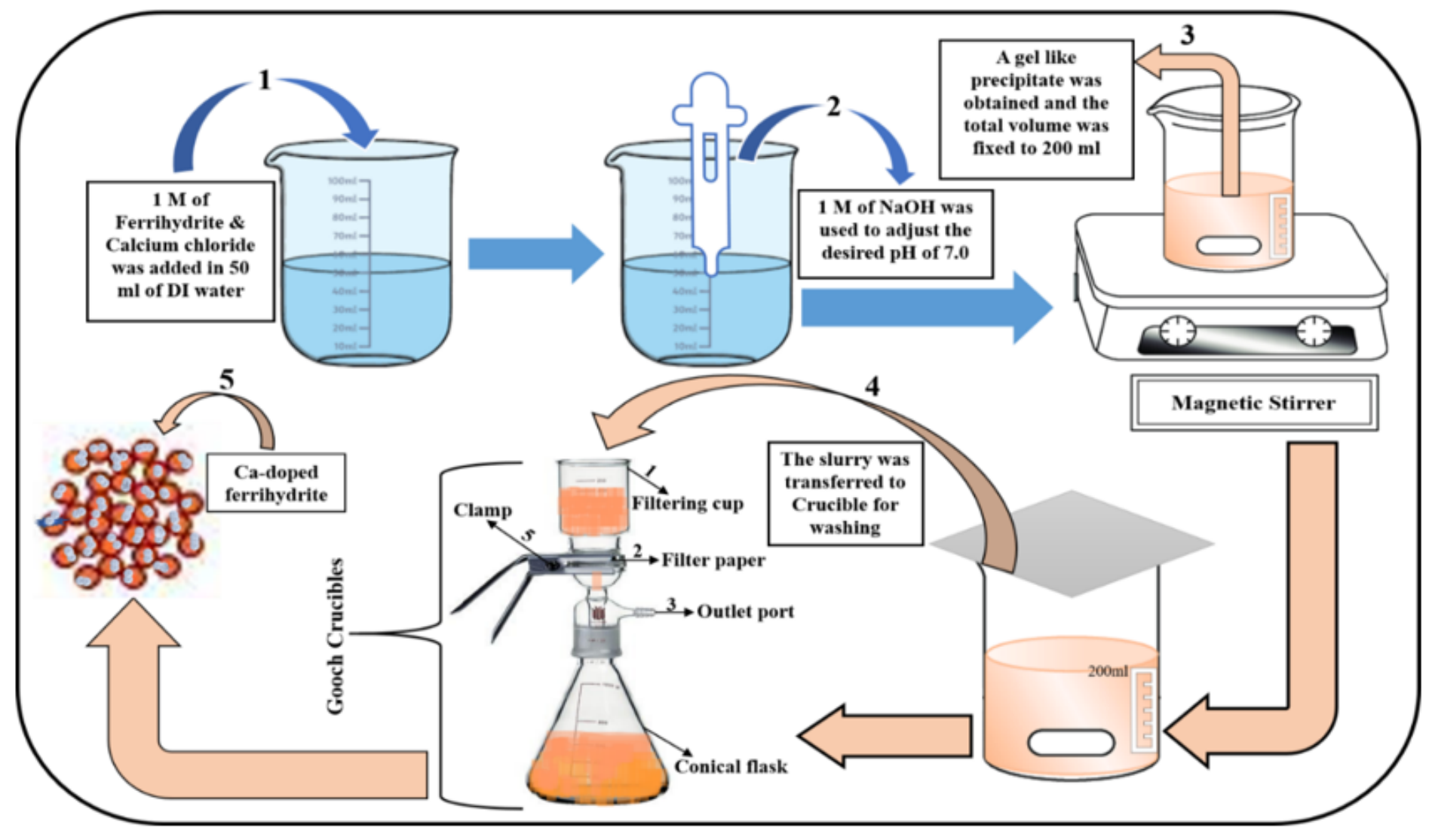

Figure 1

Schematic process of Ca-doped ferrihydrite synthesis

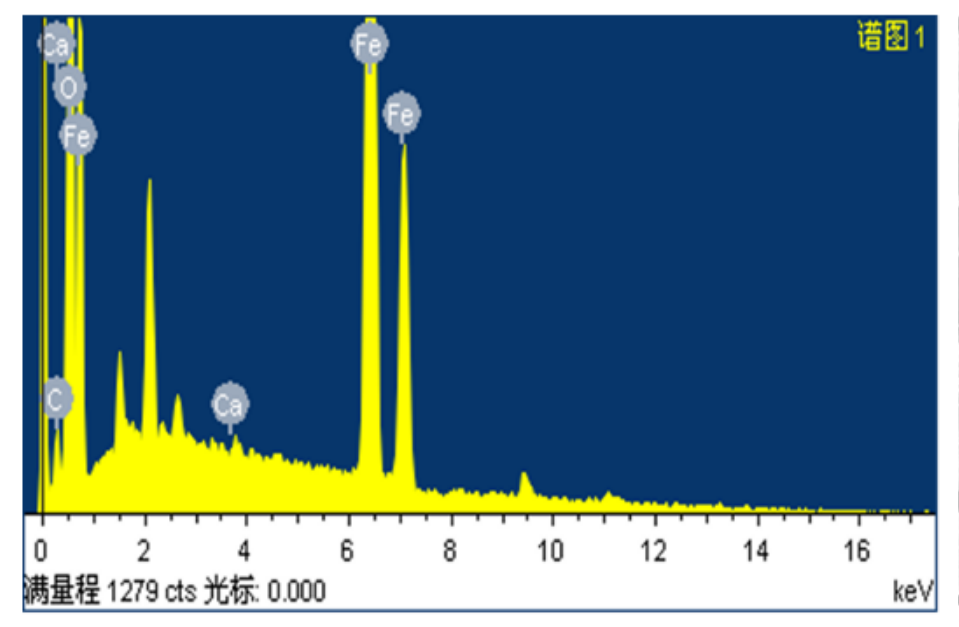

a)

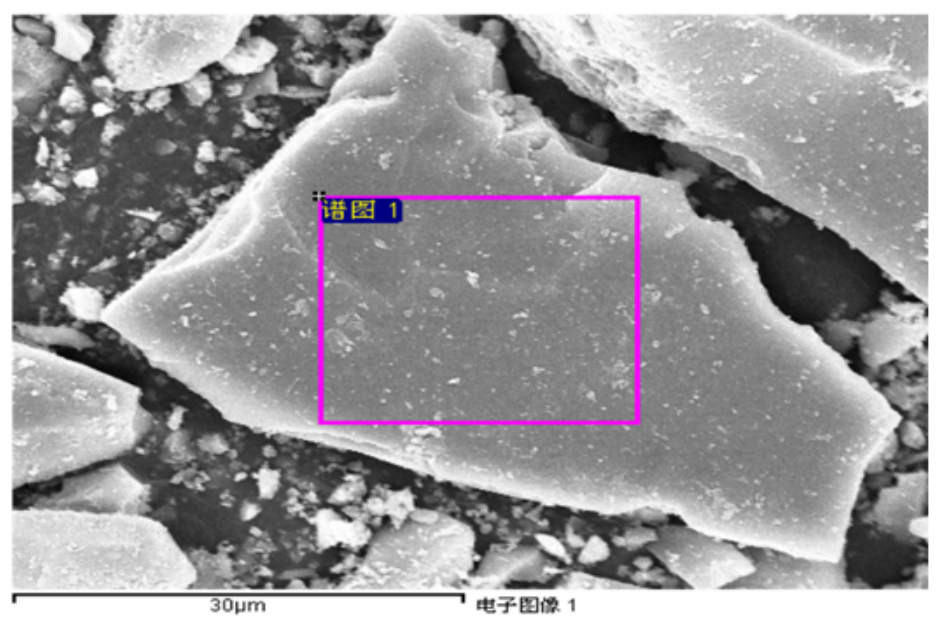

b)

\section{Figure 2}

SEM and EDX analysis of Ca-doped ferrihydrite, (a) EDX before adsorption, (b) EDX after adsorption. 


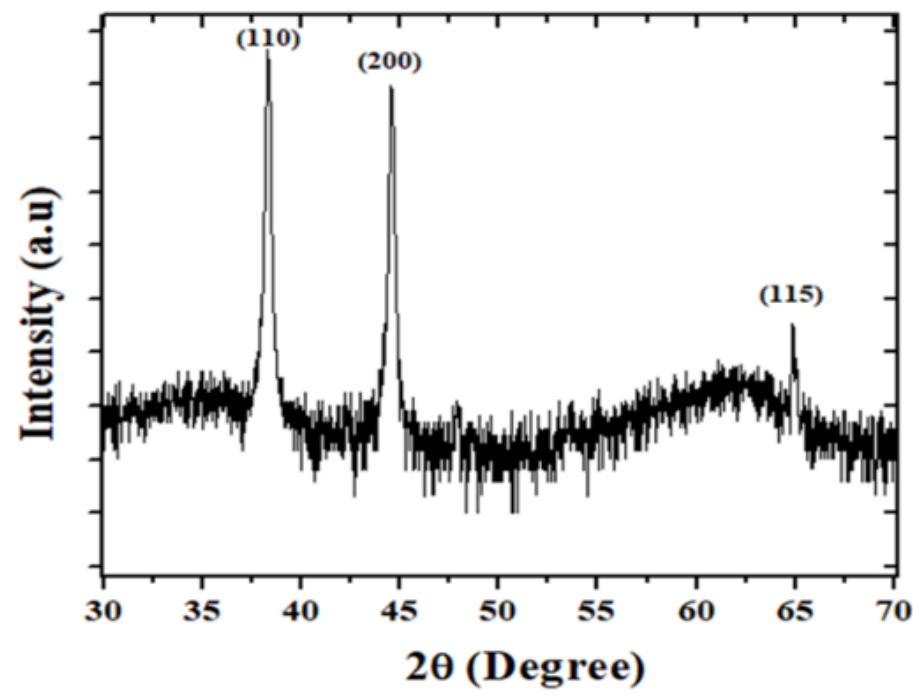

a)

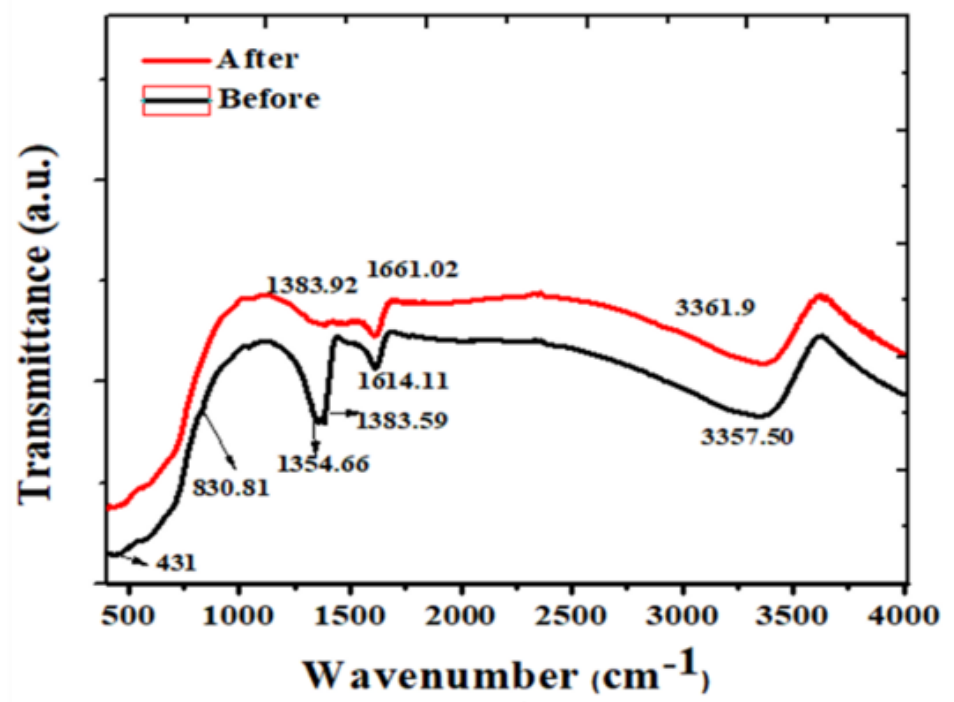

b)

Figure 3

The XRD pattern (a) and the FT-IR spectra (b) of the as-synthesized Ca-doped ferrihydrite before and after adsorption experiments.

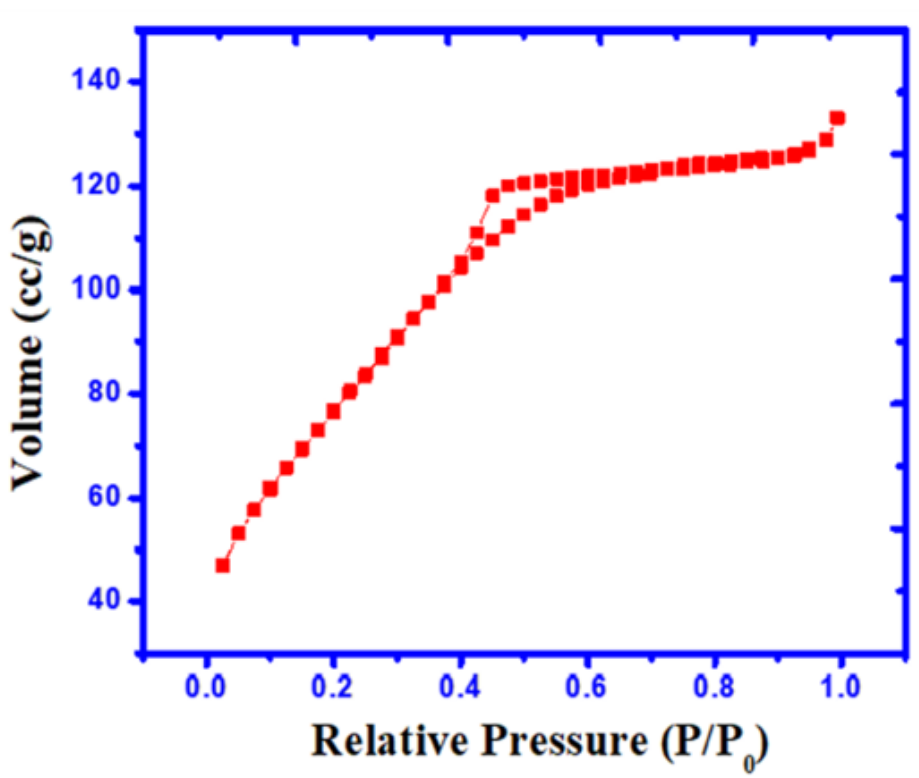

a)

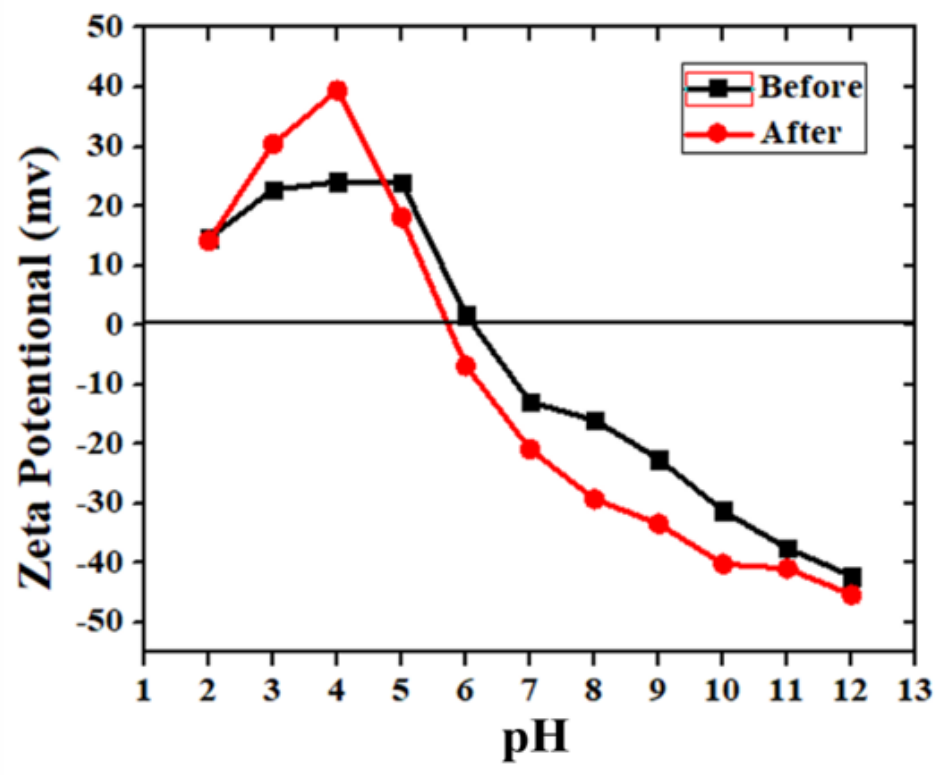

b)

Figure 4

The BET surface area (a) and the zeta potential (b) of Ca-doped ferrihydrite before and after adsorption experiments. 


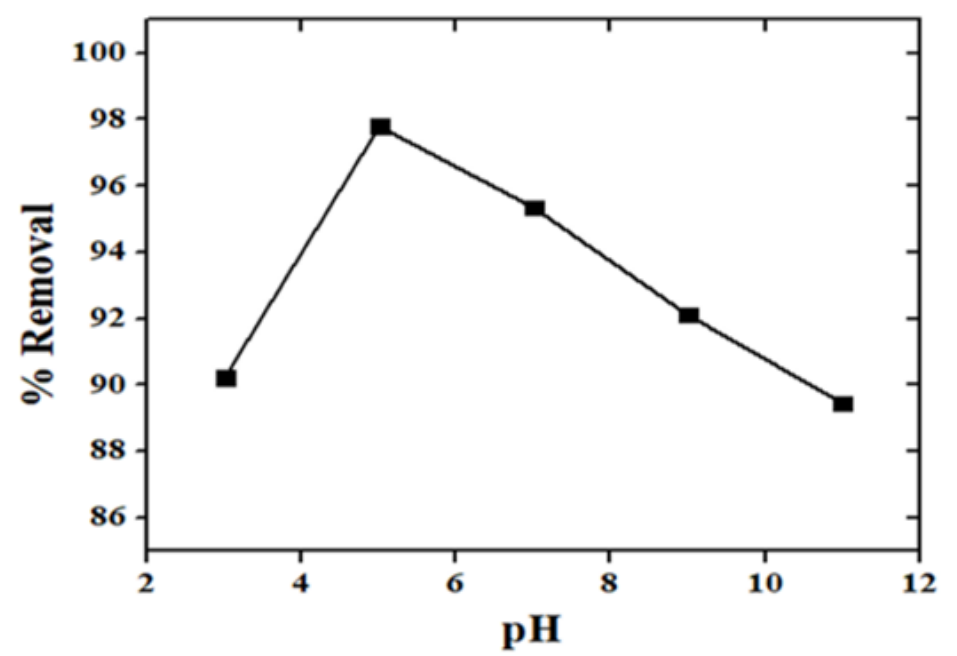

a)

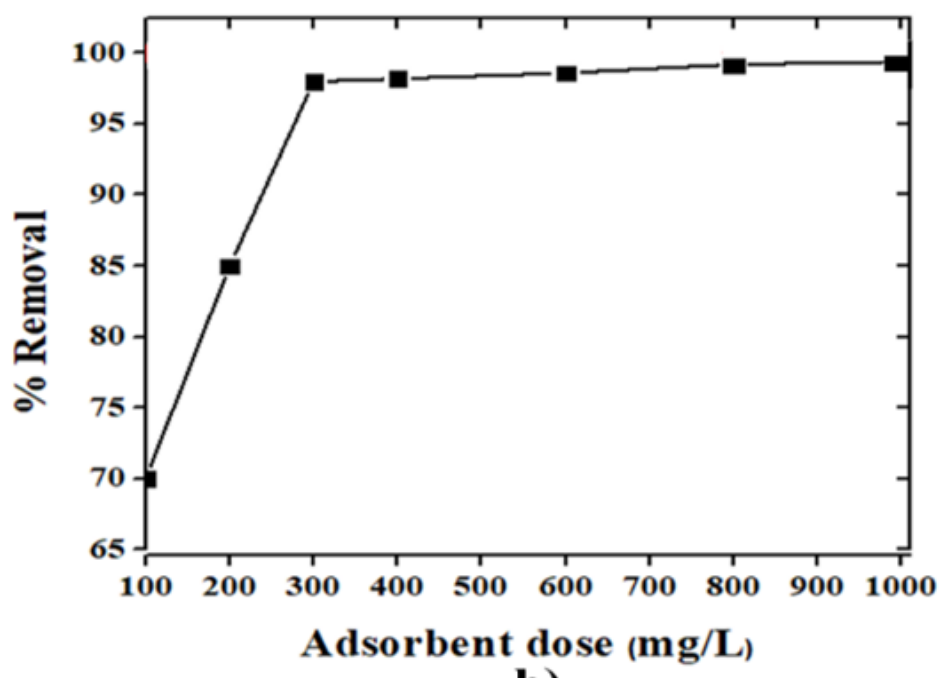

b)

Figure 5

Effects of initial pH (a) and the adsorbent dose (b) on the adsorption of fluoride by Ca-doped ferrihydrite.

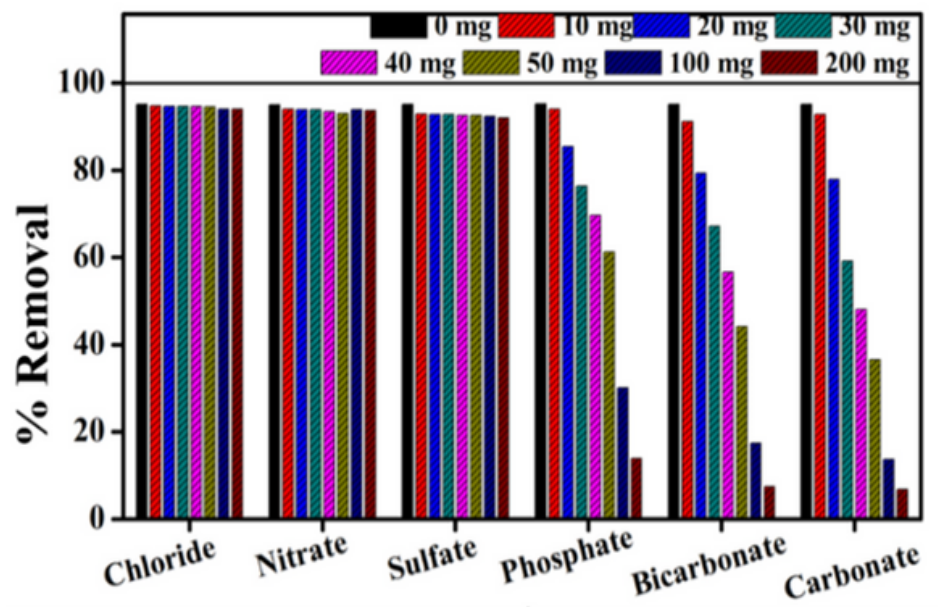

a)

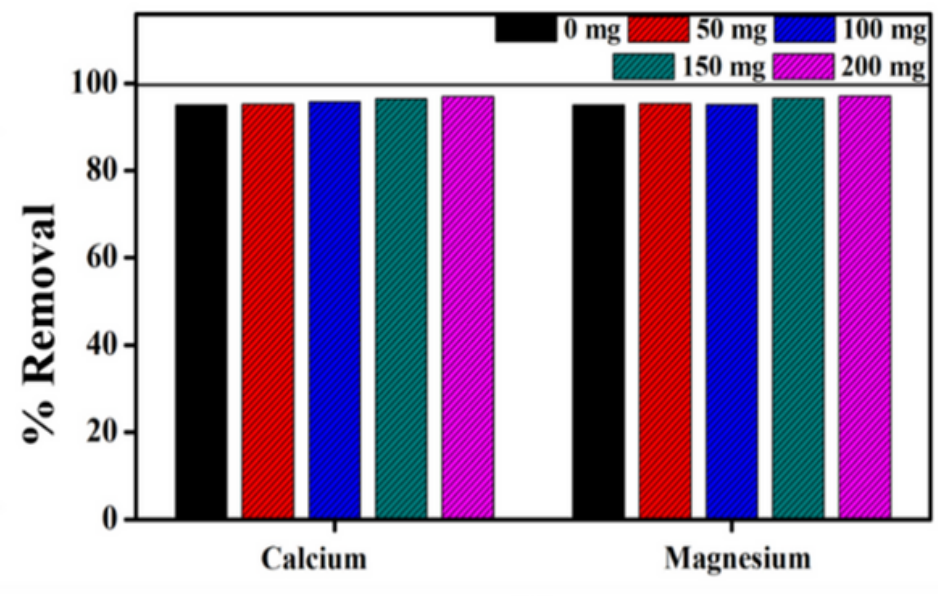

b)

Figure 6

Effect of co-existing anions ( $a$ \& c) and cations (b \& d) on the removal of fluoride by Ca-doped ferrihydrite 


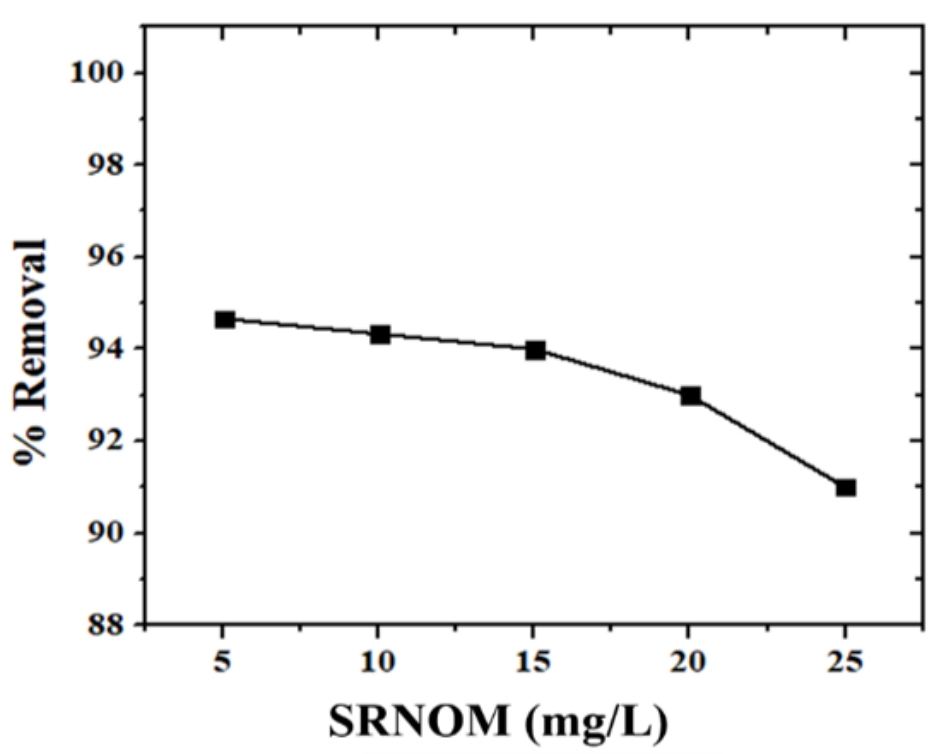

a)

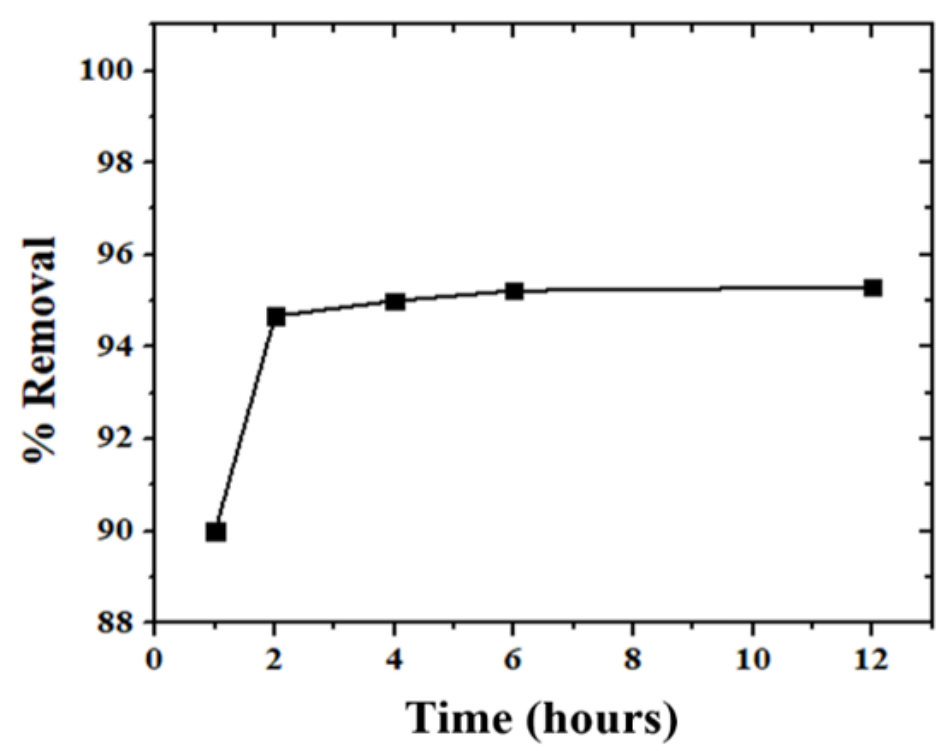

b)

Figure 7

Effect of NOM dose (a) and time (b) on the removal efficiency of fluoride by Ca-doped ferrihydrite.

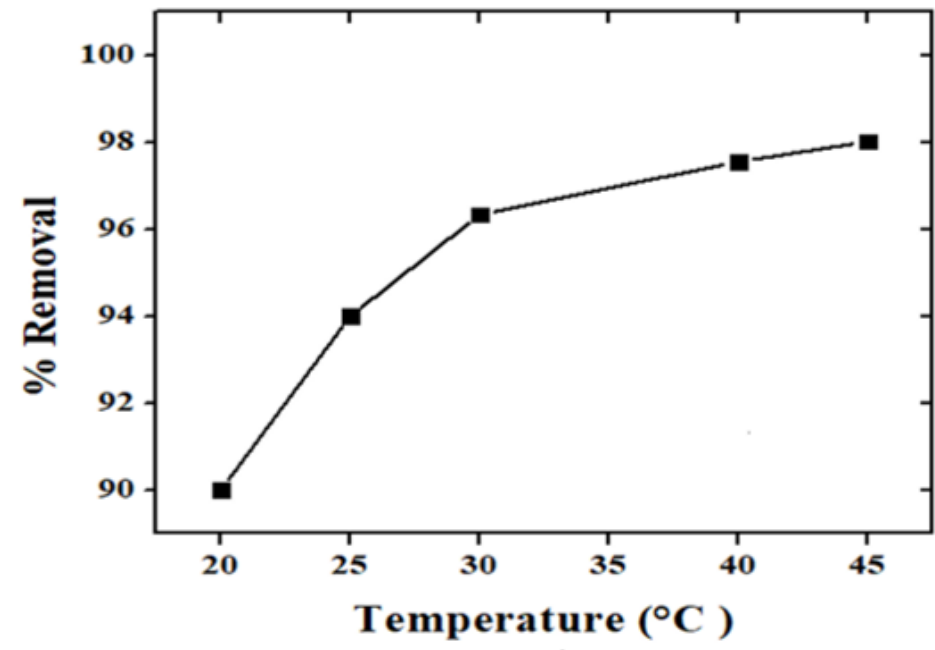

a)

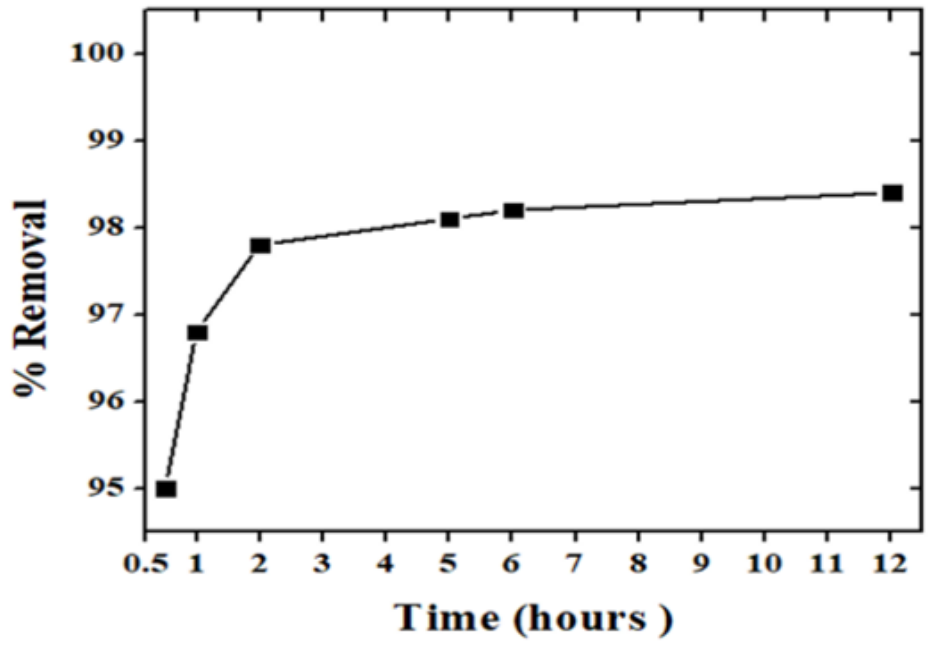

b)

Figure 8

Effect of temperature (a) and adsorption time (b) on the removal efficiency of fluoride by Ca-doped ferrihydrite. 


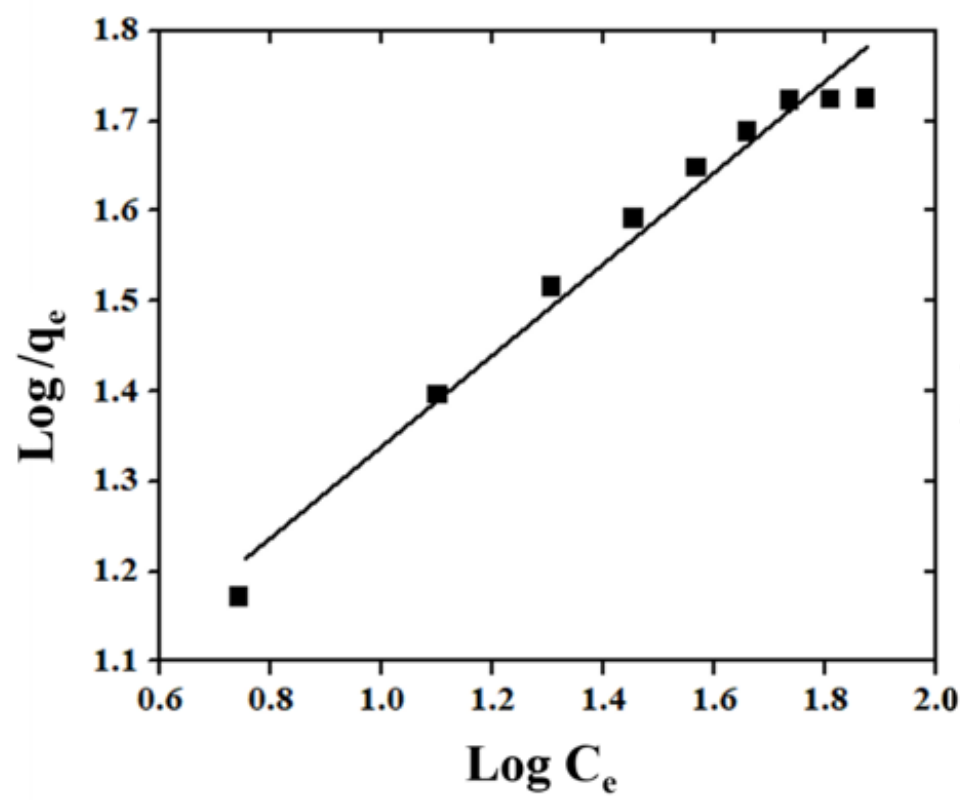

a)

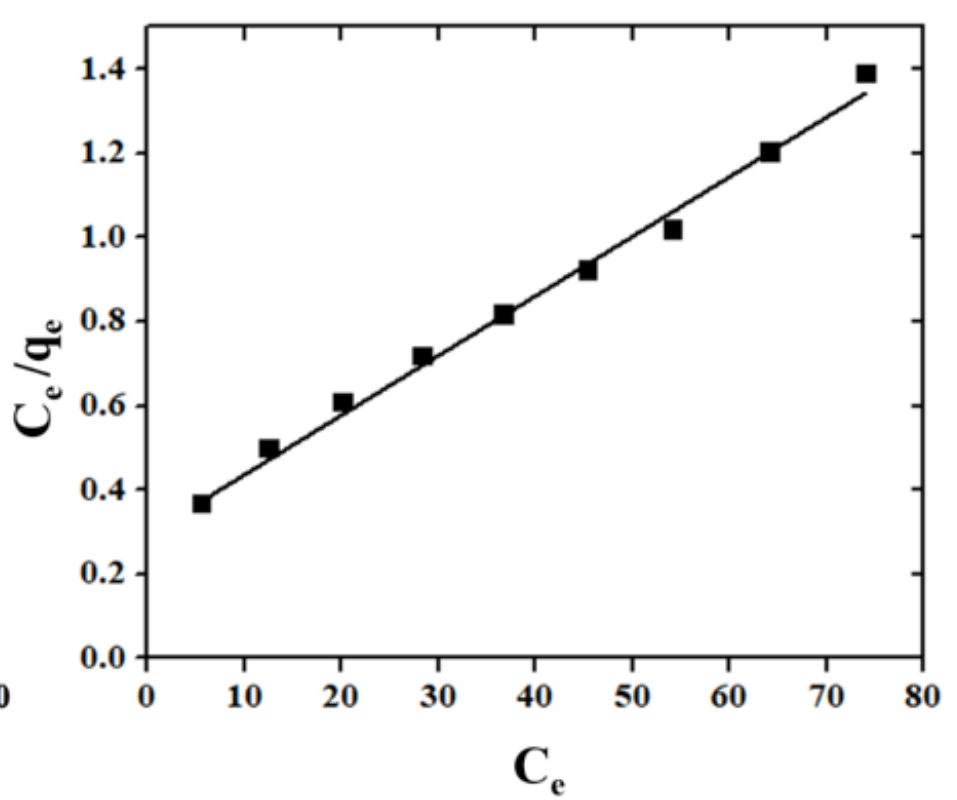

b)

Figure 9

Adsorption isotherm models for fluoride adsorption, (a) Freundlich isotherm, (b) and the Langmuir isotherm.

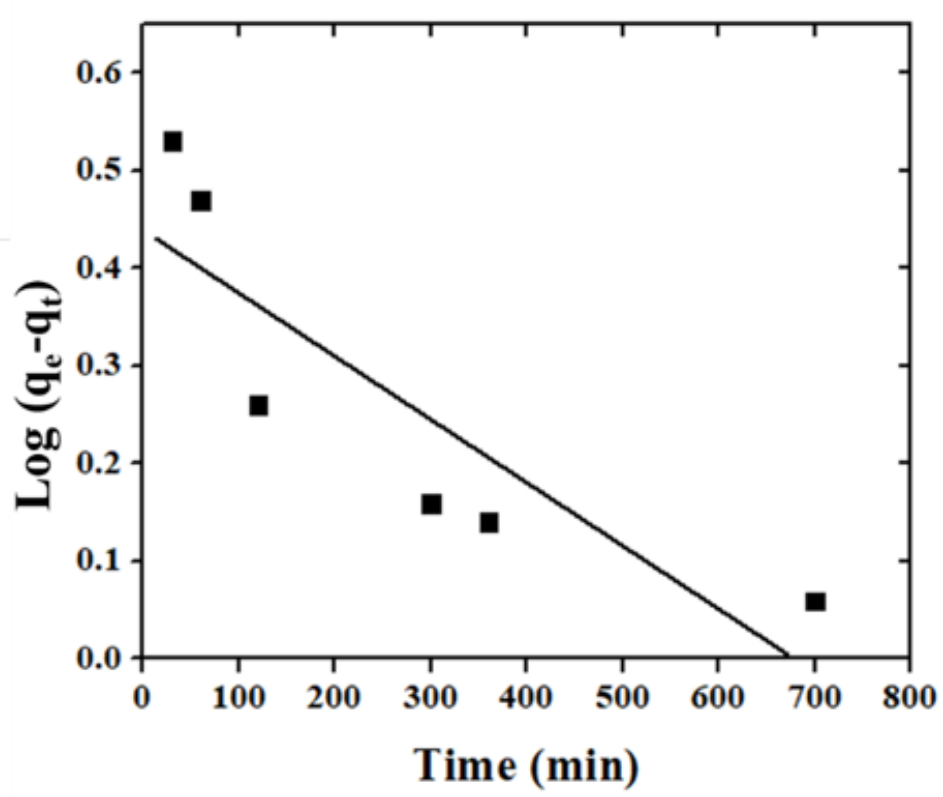

a)

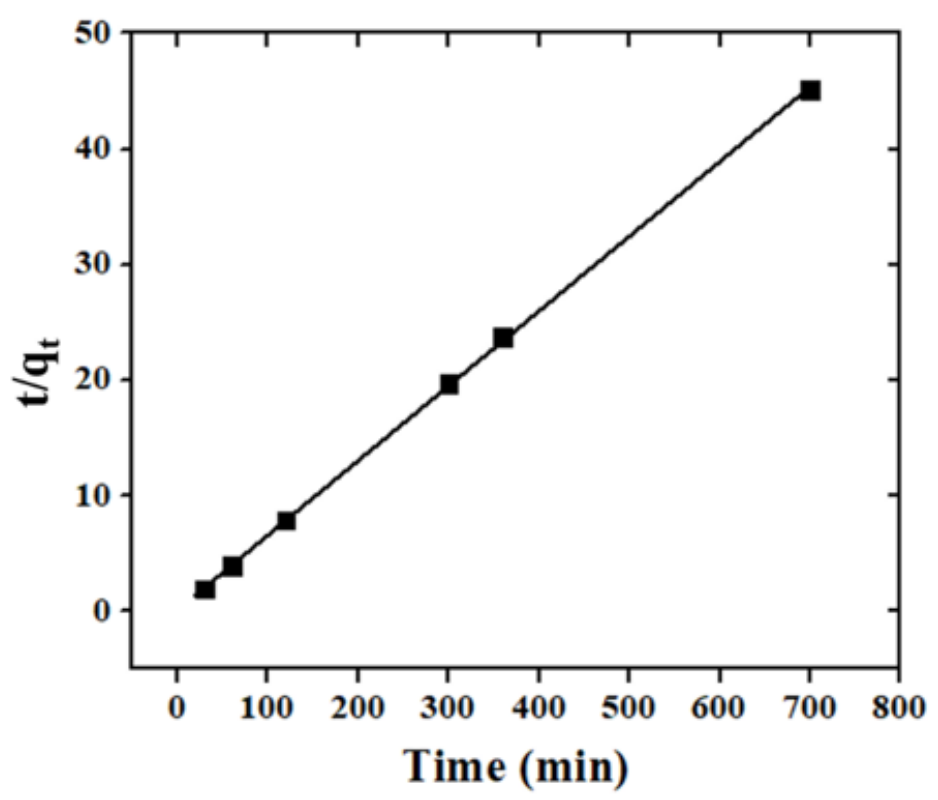

b)

Figure 10

Kinetic models, (a) the Pseudo-first order kinetic plot, (b) and the pseudo-second order kinetic plot 


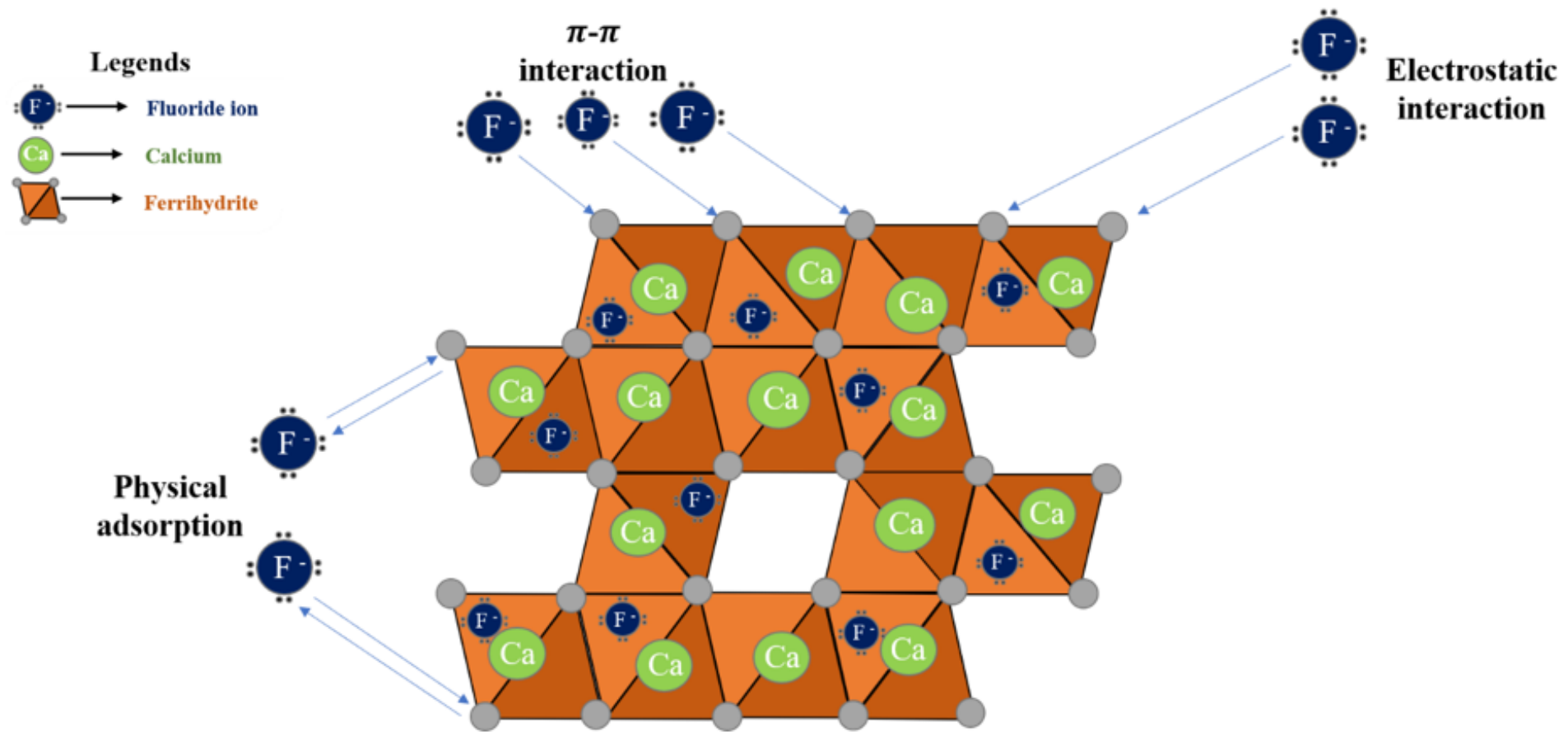

Figure 11

Proposed mechanism of fluoride adsorption onto Ca-doped ferrihydrite 


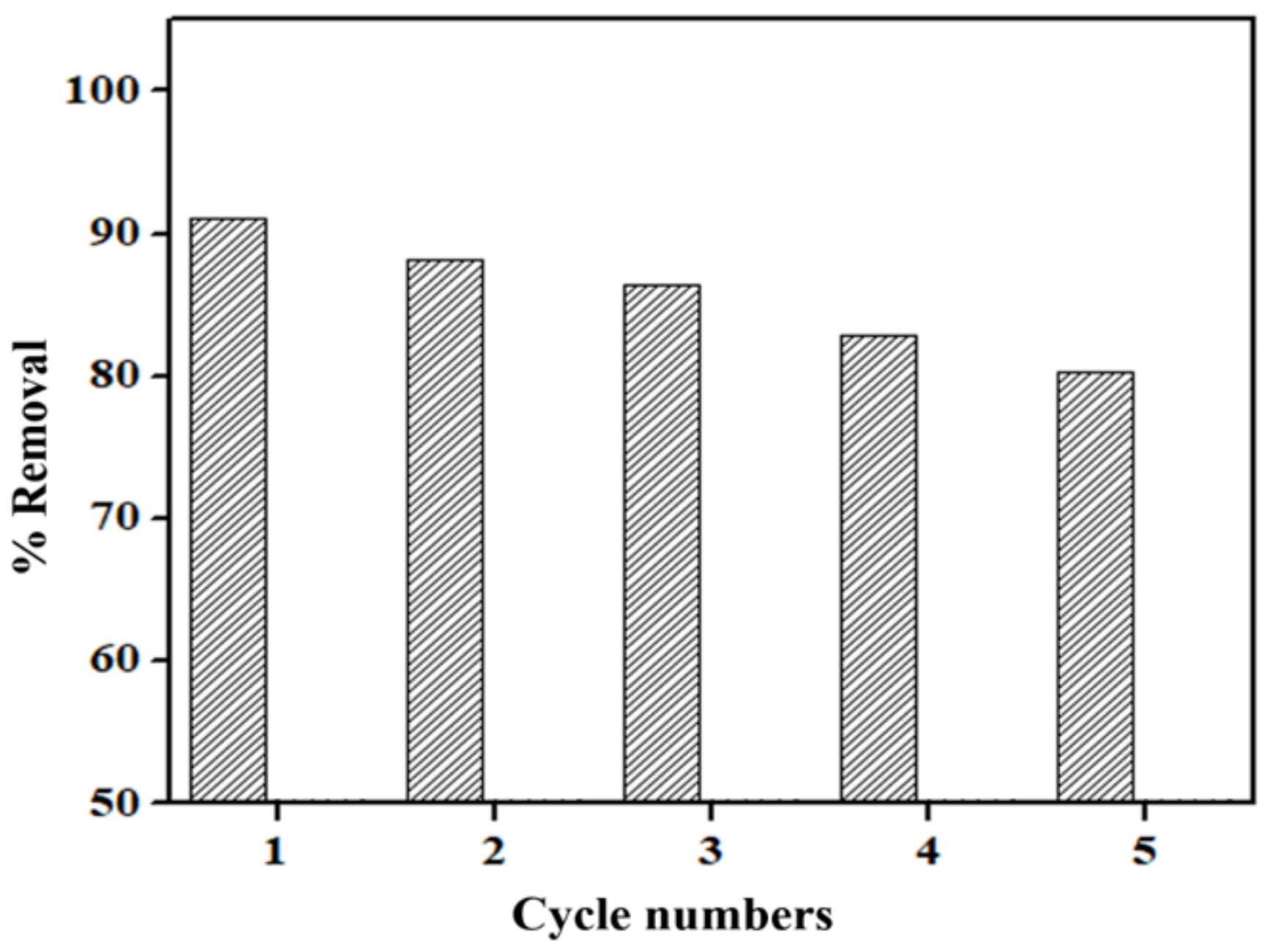

Figure 12

Regeneration of Ca-doped ferrihydrite with $0.1 \mathrm{M} \mathrm{NaOH}$ for the adsorption of fluoride.

\section{Supplementary Files}

This is a list of supplementary files associated with this preprint. Click to download.

- Graphicalabstract.docx 